\title{
The effect of rare earth element doping on the microstructural evolution of sol-gel titania powders
}

\author{
Hüsnü Arda Yurtsever*, Muhsin Çiftçioğlu \\ Department of Chemical Engineering, Izmir Institute of Technology, 35430, Izmir, Turkey
}

\section{A R T I C L E I N F O}

\section{Article history:}

Received 4 April 2016

Received in revised form

26 October 2016

Accepted 28 October 2016

Available online 31 October 2016

\section{Keywords:}

Titania

Rare earth element

Doping

Sol-gel

Nanophase evolution

\begin{abstract}
A B S T R A C T
The development of a better understanding of the low temperature nanophase evolution of high surface area titania $\left(\mathrm{TiO}_{2}\right)$ based powders is essential for their use in photocatalytic applications. A series of rare earth (RE) element doped $\mathrm{TiO}_{2}$ powders were prepared by sol-gel processing. The effects of RE doping level, ionic size and heat treatment temperature on the nanophase structure evolution and the dopant ion location in $\mathrm{TiO}_{2}$ main matrix were investigated. Anatase was determined to be the main phase up to $900{ }^{\circ} \mathrm{C}$ at all doping levels for all REs. Anatase to rutile phase transformation was inhibited by RE doping. The inhibitory effect of REs increased with increasing ionic radius. Oxide phases of La, $\mathrm{Nd}$, Pr, Sm were not present up to $5 \%$ and $\mathrm{Nd}_{4} \mathrm{Ti}_{9} \mathrm{O}_{24}$ phase was formed at $10 \%$ doping level at $800{ }^{\circ} \mathrm{C}$. The formation of $\mathrm{RE}_{2} \mathrm{Ti}_{2} \mathrm{O}_{7}$ phases were determined for the REs with relatively lower ionic radii at $800{ }^{\circ} \mathrm{C}$.
\end{abstract}

(C) 2016 Elsevier B.V. All rights reserved.

\section{Introduction}

Photocatalysis is expected to make a great contribution to both environmental treatment (emission cleaning and water purification) and renewable energy generation. Photocatalysts play a central role in the success of the photocatalytic processes. Intense research and advances in nanoscience and nanotechnology in the last 20 years improved the preparation techniques and expanded the application areas of nanostructured photocatalytic materials. Fujishima and Honda conducted the pioneering studies in 1970s for the production of renewable energy via photocatalytic processes by using solar energy [1,2]. Many photocatalytic materials since then were prepared and used in various photocatalytic processes. There is an extensive variety of materials used in many different photocatalytic processes in the literature. Titania $\left(\mathrm{TiO}_{2}\right)$ is the most widely used photocatalyst since it is inexpensive, biologically and chemically inert, stable with respect to photo/chemical corrosion.

The major disadvantage of bulk titania phases is their relatively high band gap energies commonly reported to be in the 3.0-3.2 eV range which results in a limited absorption of solar light [3]. The reduction of the band gap energies of titania phases by doping with

\footnotetext{
* Corresponding author.

E-mail addresses: husnuarda@gmail.com (H.A. Yurtsever), muhsinciftcioglu@ iyte.edu.tr (M. Çiftçioğlu).
}

various elements and the determination of the activities of these materials in the photocatalytic decomposition of organic structures constitutes the subject of concentrated research in the last 10-15 years [4-13]. Doping $\mathrm{TiO}_{2}$ with various rare earth ions can increase the photocatalytic activity by enhancing the light absorption along with tuning the phase structure and surface area/morphology. It is well known that rare earth (RE) element doping causes inhibition in the anatase to rutile phase transformation and increase in the surface area of $\mathrm{TiO}_{2}$. Research conducted in the last 10 years indicated that $\mathrm{La}, \mathrm{Nd}, \mathrm{Eu}, \mathrm{Sm}, \mathrm{Yb}$, Pr and Ce doped $\mathrm{TiO}_{2}$ showed higher activities than undoped $\mathrm{TiO}_{2}$ due to their enhanced light absorption, higher surface areas and modified nanophase structure $[6,10,12,14-16]$. These studies were mostly on environmental applications like photocatalytic degradation of dyes in wastewaters.

Research conducted on RE doped $\mathrm{TiO}_{2}$ showed no consensus on the location of the dopant ions in the $\mathrm{TiO}_{2}$ lattice in single phase [3,12,17-20] or the formation of multiphase nanomaterials [21-23]. The current understanding on the low temperature solubility limits of the $\mathrm{RE}$ ions in $\mathrm{TiO}_{2}$ phases and the related mechanisms responsible for the higher wavelength light absorption in the resultant single/multiphase nanostructures is limited and needs to be improved.

The RE ions was reported to occupy the substitutional sites in the $\mathrm{TiO}_{2}$ lattice based on X-ray Diffraction (XRD) analysis [24-29]. In a number of other research papers it was concluded that substitutional incorporation of RE ions is not possible due to the 
significantly larger ionic radii compared to the $\mathrm{Ti}^{4+}$ ion and the $\mathrm{RE}$ ions can accommodate in the interstitials or segregate as oxide/ hydroxide phases on the grain boundaries of $\mathrm{TiO}_{2}[20,30]$. There are also studies indicating the formation of a new phase containing both RE and titanium ions [31,32]. It was reported that anatase to rutile phase transformation was significantly inhibited by RE ions and the inhibitory effect was observed to increase with the dopant ionic radii along with the formation of different RETiO phases [32].

Systematic research efforts on the effect of RE doping on sol particle size and nanophase structure characteristics such as secondary phase formations, crystallite size, lattice constants, lattice strain, anatase-rutile weight fraction are currently limited. In addition phase diagrams of $\mathrm{TiO}_{2}$ with RE oxides are present for heat treatment temperatures above $1000^{\circ} \mathrm{C}$ and these diagrams indicate that two phases are insoluble in each other [33,34]. These phase diagrams show that there are oxide phases of $\mathrm{RE}_{2} \mathrm{Ti}_{2}, \mathrm{RE}_{4} \mathrm{Ti}_{9}, \mathrm{RE}_{2} \mathrm{Ti}_{4}$ which may be formed at high RE contents and temperatures. The low temperature structure of these phase diagrams is very important since it is crucial to maintain high surface area and porous structure of the nanomaterials in photocatalytic applications. A nanophase structure consisting of a mixture of anatase and rutile phases is also reported to exhibit high photocatalytic activity. The origin of better photocatalytic activity of anatase-rutile mixtures compared to pure anatase phase were reported to be the formation of heterojunctions in the nanostructure [35], the stabilization of charge separation and the lower band gap energy of rutile phase [36]. The low temperature $\mathrm{RE}$ oxide- $\mathrm{TiO}_{2}$ phase diagrams would be useful in the preparation of multiphase $\mathrm{TiO}_{2}$ photocatalysts with nanoscale mixing of anatase and rutile phases by varying the doping level and heat treatment temperature. The low temperature $\mathrm{RE}$ oxide- $\mathrm{TiO}_{2}$ phase diagrams are not currently present to the best of our knowledge. A better understanding of the nature of the nanophase structure and solid state solubility at low RE doping levels and low temperatures would contribute significantly to the assessment of the photocatalytic activity of $\mathrm{RE}$ doped $\mathrm{TiO}_{2}$ or RE-Ti mixed oxides.

RE incorporated $\mathrm{TiO}_{2}$ based nanostructured materials were prepared by using sol-gel processing in order to clarify the effect of $\mathrm{RE}$ doping on the nanophase structure evolution in $\mathrm{TiO}_{2}$ powders in this study. A better understanding on these issues may develop an ability to nanodesign the desired material towards a specific application. Nanophase structure characteristics of these materials were investigated along with the effect of the dopant ions on initial sol particle size, crystallite size and surface area. The low temperature tentative phase diagrams of $\mathrm{RE}$ oxide- $\mathrm{TiO}_{2}$ systems in the temperature-composition plane were also experimentally determined.

\section{Materials and methods}

\subsection{Powder preparation}

RE doped $\mathrm{TiO}_{2}$ powders were prepared by sol-gel using titanium tetraisopropoxide (TTIP, Aldrich 97\%) as titanium precursor. Nitrate hexahydrates of Ce, Nd, La, Pr, Gd (Aldrich), nitrate pentahydrates of $\mathrm{Er}, \mathrm{Tb}, \mathrm{Eu}, \mathrm{Yb}$ (Aldrich), nitrate hexahydrate of Sm (Alfa aesar), nitrate pentahydrate of Dy (Alfa aesar), all $\geq 99.9$ on trace metal basis were used as dopant precursors.

Undoped $\mathrm{TiO}_{2}$ powders were prepared by the dropwise addition of a solution of nitric acid $\left(\mathrm{HNO}_{3}\right.$, Merck $\left.65 \%\right)$ and water in ethanol (Merck absolute) to a titanium tetraisopropoxide/ethanol (TTIP/ EtOH) solution under vigorous stirring at room temperature. The resulting transparent sol with final molar TTIP: $\mathrm{H}_{2} \mathrm{O}: \mathrm{HNO}_{3}: \mathrm{EtOH}$ ratio of $1: 2: 0.06: 5.9$ was stirred until complete gelation was obtained. The $\mathrm{Ti}^{4+}$ concentration was $0.9 \mathrm{M}$ in the final sol. RE doped
$\mathrm{TiO}_{2}$ powders were prepared by following the same route with the addition of predetermined amounts of RE nitrates to nitric acid/ water/ethanol solution. The water in the RE nitrate hydrates were also accounted for in the sol formulations. The obtained gels were dried at $50^{\circ} \mathrm{C}$ overnight prior to heat treatment at $400-1000^{\circ} \mathrm{C}$ for $3 \mathrm{~h}$. $\mathrm{TiO}_{2}$ powders doped with $0-10 \% \mathrm{RE}_{2} \mathrm{O}_{3}\left(\mathrm{CeO}_{2}\right.$ for Ce doping) on total oxide molar basis $\left(\mathrm{TiO}_{2}+\mathrm{RE}_{2} \mathrm{O}_{3}\right)$ were prepared in the context of this study.

Gelation time for undoped $\mathrm{TiO}_{2}$ was 3 min whereas it increased up to 4 days with increasing doping level for the doped $\mathrm{TiO}_{2}$ sols. The increase in the gelation time with doping level may be due to the increase in the nitrate ion concentration originating from the use of the nitrate salts of REs as dopant precursors.

\subsection{Characterization}

Phase characterization of the prepared powders was performed by Philips X'pert Pro XRD equipment with monochromated highintensity $(\lambda=1.54 \AA) \mathrm{CuK} \alpha$ radiation. The scanning rate was 2.5 $2 \Theta /$ min between $5^{\circ}$ and $80^{\circ}$ with $0.033^{\circ}$ step size. Characterization was conducted with 1-2 $\mathrm{g}$ of powder pressed in an aluminum cassette which was also used as reference material to calculate the accurate peak positions.

The crystallite sizes were calculated from the broadening of the (101) reflection for anatase and (110) reflection for rutile using Scherrer's equation:

$$
\mathrm{d}=\frac{\mathrm{k} \cdot \lambda}{\beta \cdot \cos \theta}
$$

where $d$ is the crystallite size $(\mathrm{nm}), \mathrm{k}$ is the shape constant ( 0.9 for spherical particles), $\lambda$ is the X-ray wavelength (nm), $\beta$ is the full width at half maximum (FWHM) of the selected peak and $\theta$ is the Bragg's angle of diffraction.

The rutile and anatase weight fractions were determined by using the following relation:

$\mathrm{x}_{\mathrm{A}}=\left(1+1.26 \frac{\mathrm{I}_{\mathrm{R}}}{\mathrm{I}_{\mathrm{A}}}\right)^{-1}$

where $\mathrm{x}_{\mathrm{A}}$ is the anatase weight fraction, $\mathrm{I}_{\mathrm{R}}$ and $\mathrm{I}_{\mathrm{A}}$ are the intensities of the rutile (110) and anatase (101) peaks, respectively [37].

The determination of the crystal lattice constants for tetragonal geometry ( $\mathrm{a}$ and $\mathrm{c}$ ) was conducted using the following expression:

$\frac{1}{\mathrm{~d}_{\mathrm{hkl}}^{2}}=\frac{\mathrm{h}^{2}+\mathrm{k}^{2}}{\mathrm{a}^{2}}+\frac{\mathrm{l}^{2}}{\mathrm{c}^{2}}$

where $d_{h k l}$ is the interplanar spacing and hkl are the Miller (plane) indices. The lattice constants were determined by selecting two peaks (101 and 200 for anatase) [38].

The $\mathrm{TiO}_{2}$ crystal lattice strains were calculated by using Williamson-Hall $(\mathrm{W}-\mathrm{H})$ plots with at least 4 diffraction peaks to be used in the following relation:

$\frac{\beta \cos \theta}{\lambda}=\frac{1}{\sigma}+\frac{\eta \cdot \sin \theta}{\lambda}$

where $\sigma$ is the effective particle size and $\eta$ is the effective lattice strain [38].

The effect of RE doping on $\mathrm{TiO}_{2}$ sol average particle sizes were determined by Dynamic Light Scattering (DLS) measurements with Malvern NanoZS90. The EtOH:TTIP ratio was increased to about 24 for Nd doped $\mathrm{TiO}_{2}$ sols keeping $\mathrm{Ti}^{4+}: \mathrm{H}_{3} \mathrm{O}^{+}: \mathrm{H}_{2} \mathrm{O}$ ratio constant.

The existence and bonding states of the elements in the 
prepared powders were identified by using X-ray Photoelectron Spectroscopy (XPSSPECS EA 300). Carbon C1s line at $284.8 \mathrm{eV}$ was chosen as a reference for the correction of the peak positions. The C1s, Ti2p and 01s spectra were fitted with a 70\% Gaussian-30\% Lorentzian product function peak shape model (GL30) in combination with a Shirley background by using XPS Peak Fit 4.1 software program. Quantitative analyses for the calculation of O:Ti atomic ratios were performed by using the corresponding peak areas and the atomic sensitivity factors of lattice $01 \mathrm{~s}$ and $\mathrm{Ti} 2 \mathrm{p}_{3 / 2}$ as 0.66 and 1.2 , respectively [39].

Nitrogen adsorption-desorption isotherms and surface areas were determined by Micromeritics Gemini V surface area analyzer. Powders were degassed overnight at $300{ }^{\circ} \mathrm{C}$. High Resolution Transmission Electron Microscopy (HR-TEM, Jem Jeol 2100F $200 \mathrm{kV}$ ) and Transmission Electron Microscopy-Energy Dispersive $\mathrm{X}$-ray (TEM-EDX) was used to investigate the nanophase structure and the nature of the present phases in the synthesized powders. Image $1.50 \mathrm{~b}$ software program was used to determine the crystallite sizes and to obtain Fast Fourier Transform (FFT) of the corresponding HR-TEM images.

\section{Results and discussion}

\subsection{Nanophase evolution of undoped $\mathrm{TiO}_{2}$ powders}

The XRD patterns, crystallite sizes, rutile weight percentages, lattice strains (slopes of $\mathrm{W}-\mathrm{H}$ plots) and structural parameters (lattice constants, cell volume and tetragonality) calculated by using XRD patterns and equations (1)-(4) of undoped $\mathrm{TiO}_{2}$ powders are given in Fig. 1 and Table 1, respectively. The anatase phase was found to be the only phase in the $400-600{ }^{\circ} \mathrm{C}$ range. Anatase and rutile coexist at $700{ }^{\circ} \mathrm{C}$ and only rutile phase is present at $800{ }^{\circ} \mathrm{C}$ and above heat treatment temperatures. Anatase to rutile phase transformation onset temperature was estimated to be in the $600-700{ }^{\circ} \mathrm{C}$ temperature interval according to the XRD patterns. This temperature was reported to be around $600{ }^{\circ} \mathrm{C}$ in a review paper published in 2011 [40]. However there are studies reporting that phase transformation may start at relatively lower temperatures (lower than $450{ }^{\circ} \mathrm{C}$ ) depending on the chemicals, their purity and the powder synthesis method [41,42]. The powder crystallite size increased from 15 to over $100 \mathrm{~nm}$ while lattice strain decreased with increasing heat treatment temperature. A negative slope in the $\mathrm{W}-\mathrm{H}$ plot indicates the presence of compressive strain, while a positive slope indicates the presence of tensile strain [43]. Slopes of the $\mathrm{W}-\mathrm{H}$ plots of undoped $\mathrm{TiO}_{2}$ powders were positive up to $700^{\circ} \mathrm{C}$ and were negative for the temperature interval of $700-1000{ }^{\circ} \mathrm{C}$. The powders formed from anatase phase showed tensile strain while powders containing rutile phase showed compressive strain which may be due to the phase transformation/densification and grain growth. Lattice constants varied with heat treatment temperature as seen in Table 1. Lattice constant $c$ and unit cell volume of anatase phase increased with the heat treatment temperature where lattice constant a remained almost constant. This may be attributed to the increase in crystallinity and crystallite size of the anatase phase. The changes in the rutile phase lattice constants were negligible for these heat treatment temperatures.

\subsection{The effect of RE doping on $\mathrm{TiO}_{2}$ sol particle size}

The variation in sol particle size with aging time and Nd doping level is given in Fig. 2a where the sol particle sizes of freshly prepared sols are labeled as $0^{\text {th }}$ day. The effect of doping level on sol particle size distribution after aging for 8 days is given in Fig. 2 b. The sol particle sizes varied with doping level. The volume average sol particle size increased with $\mathrm{Nd}$ doping level and aging time. The sol particle size distributions after aging for 8 days shifted to
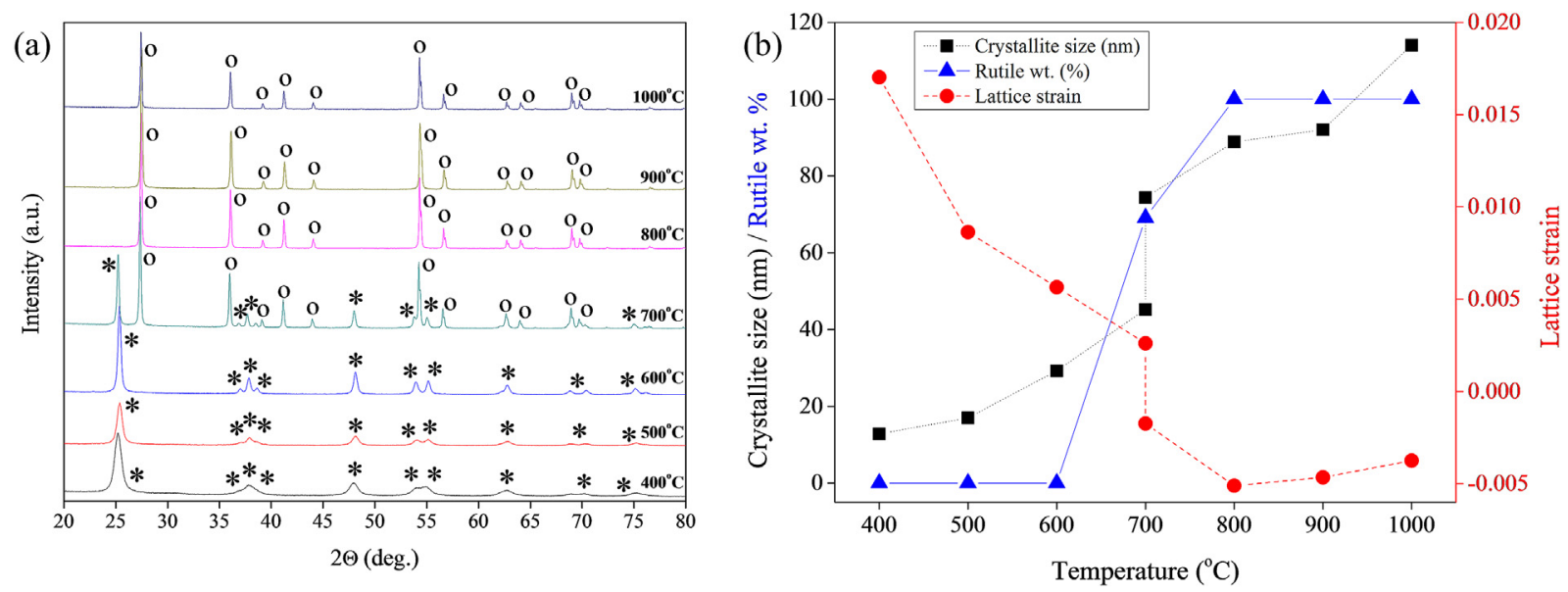

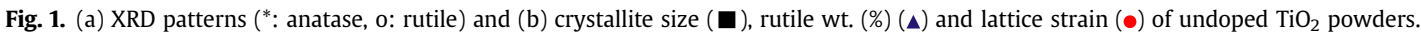

Table 1

Structural parameters of undoped $\mathrm{TiO}_{2}$ powders calculated by using XRD patterns.

\begin{tabular}{|c|c|c|c|c|c|}
\hline Temperature $\left({ }^{\circ} \mathrm{C}\right)$ & Phase & Lattice parameter a $(\AA)$ & Lattice parameter c $(\AA)$ & Cell volume $\left(\AA^{3}\right)$ & Tetragonality (c/a) \\
\hline 400 & Anatase & 3.78 & 9.38 & 133.71 & 2.48 \\
\hline 500 & Anatase & 3.78 & 9.49 & 135.66 & 2.51 \\
\hline 600 & Anatase & 3.78 & 9.58 & 136.87 & 2.53 \\
\hline 700 & Anatase & 3.78 & 9.60 & 137.10 & 2.54 \\
\hline 700 & Rutile & 4.61 & 2.97 & 63.00 & 0.64 \\
\hline 800 & Rutile & 4.60 & 2.96 & 62.53 & 0.64 \\
\hline 900 & Rutile & 4.60 & 2.96 & 62.72 & 0.64 \\
\hline 1000 & Rutile & 4.60 & 2.96 & 62.54 & 0.64 \\
\hline
\end{tabular}



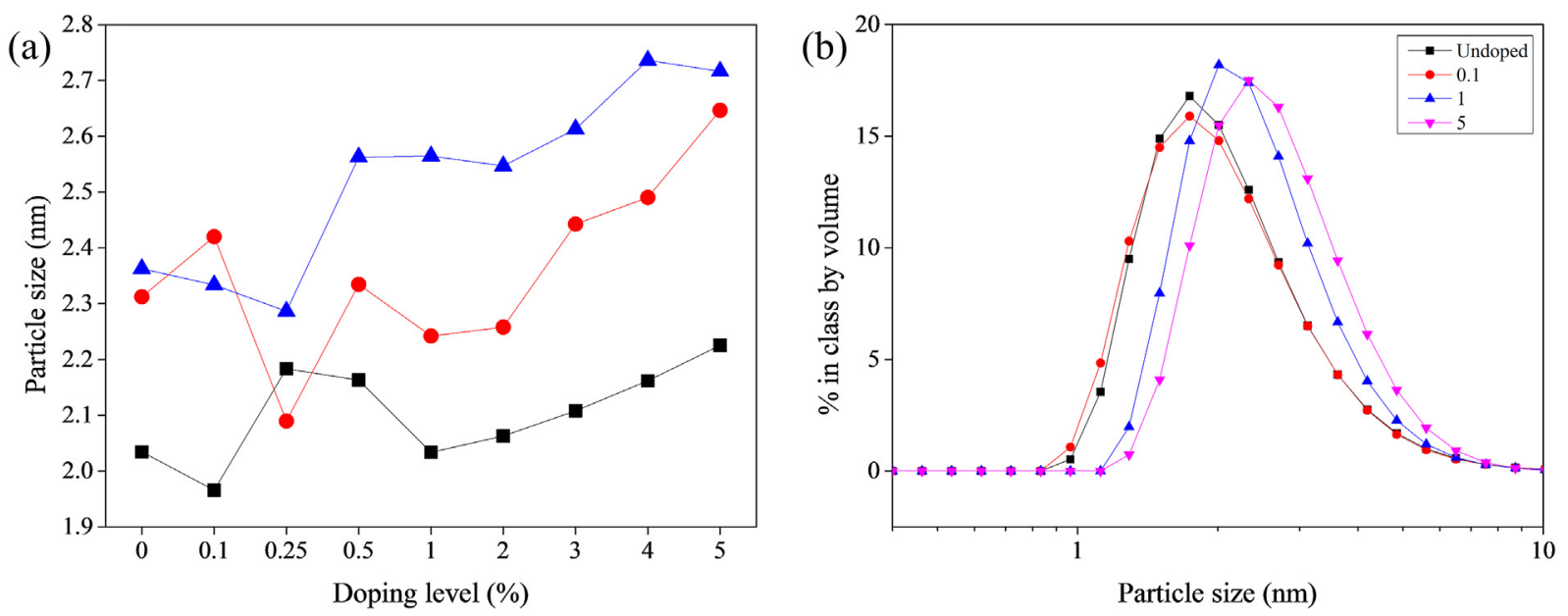

Fig. 2. (a) Particle sizes of $\mathrm{Nd}$ doped $\mathrm{TiO}_{2}$ sols ( $\boldsymbol{\square}$ : 0th day, $\bullet$ : 1 st day, $\mathbf{\Lambda}$ : 8 th day) and (b) Particle size distribution of $\mathrm{Nd}_{\text {doped }} \mathrm{TiO} \mathrm{O}_{2}$ sols on the 8 th day.

slightly higher sol particle sizes with doping. $\mathrm{TiO}_{2}$ sol particle size remained constant at low doping levels (at 0.1 and $0.25 \%$ ) and increased at higher doping levels in general. The average particle size range of freshly prepared $\mathrm{TiO}_{2}$ sols were determined to increase from $\sim 2 \mathrm{~nm}$ to $\sim 2.6 \mathrm{~nm}$ at the end of 8 days of aging. The activation energy and the onset temperature for phase transformation decreases with decreasing initial particle size leading to decreased thermal stability $[44,45]$ and the particle size of $\mathrm{TiO}_{2}$ sols was reported to be either reduced or increased by doping $[46,47]$.

\subsection{Nanophase evolution of $\mathrm{Nd}$ or $\mathrm{Er}$ doped $\mathrm{TiO}_{2}$ powders}

XRD patterns of Nd doped $\mathrm{TiO}_{2}$ powders heat treated in the $400-1000{ }^{\circ} \mathrm{C}$ temperature range are given in Fig. 3. Anatase was found to be the main phase in all $\mathrm{Nd}$ doped $\mathrm{TiO}_{2}$ powders in the $400-800{ }^{\circ} \mathrm{C}$ heat treatment temperature range. The powders heat treated in the $400-600{ }^{\circ} \mathrm{C}$ range were pure anatase. Rutile phase was detected at $700{ }^{\circ} \mathrm{C}$ and $800{ }^{\circ} \mathrm{C}$ heat treatment temperature up to $0.25 \%$ and $0.5 \%$ doping levels, respectively. $\mathrm{Nd}_{4} \mathrm{Ti}_{9} \mathrm{O}_{24}$ phase was detected in $10 \% \mathrm{Nd}$ doped $\mathrm{TiO}_{2}$ powder at $800{ }^{\circ} \mathrm{C}$. The relative intensity of the (101) anatase peak significantly decreased and FWHM of this peak increased with increasing doping level. This indicated a retarded nanophase evolution with increased $\mathrm{Nd}$ doping level. The absence of rutile phase peaks above certain doping levels in the $600-800{ }^{\circ} \mathrm{C}$ range also indicated a significant inhibition of the anatase to rutile phase transformation.

The ionic radius of $\mathrm{RE}^{3+}$ (>100 p.m.) is between that of $\mathrm{Ti}^{4+}(68$ p.m.) and $\mathrm{O}^{2-}\left(132\right.$ p.m.). Therefore, it is difficult for $\mathrm{RE}^{3+}$ ions to substitute the $\mathrm{Ti}^{4+}$ ions in the lattice [48]. It is likely for $\mathrm{RE}^{3+}$ ions to accommodate in the interstitials or segregate in the grain boundaries in the form of oxide/hydroxide phases depending on the concentration of RE ions [23] and heat treatment temperature. There may be three possible mechanisms for the anatase to rutile phase transformation inhibition. The presence of interstitial more electropositive $\mathrm{Nd}^{3+}$ ions (compared to $\mathrm{Ti}^{4+}$ ) [19] may create localized positive charge around $\mathrm{Ti}^{4+}$ ions. The diffusion barrier created by the segregated RE-oxide/hydroxide phases on the $\mathrm{TiO}_{2}$ grain boundaries may decrease the contacts necessary for grain growth and phase transformation [49]. The final possible mechanism may be the substitution of $\mathrm{Ti}^{4+}$ ions for $\mathrm{Nd}^{3+}$ ions in $\mathrm{Nd}$-oxide/ hydroxide lattice on the interface of $\mathrm{Nd}^{3+}-\mathrm{TiO}_{2}$ and the formation of $\mathrm{Nd}-\mathrm{O}-\mathrm{Ti}$ bonds which stabilize the $\mathrm{Ti}-\mathrm{O}$ bonds and inhibit $\mathrm{Ti}-\mathrm{O}$ bond breakage needed for anatase/rutile crystal nucleation/growth [50]. Stabilization of $\mathrm{Ti}-\mathrm{O}$ bond by $\mathrm{Nd}$ doping may lead to a decrease in the atomic mobility which may also lead to the inhibition of anatase to rutile phase transformation. Studies conducted in the last 2-3 years have shown that RE ions may inhibit anatase to rutile phase transformation by the above mentioned mechanisms [51-53].

Formation of $\mathrm{Nd}_{4} \mathrm{Ti}_{9} \mathrm{O}_{24}$ phase at $10 \%$ doping level and $800{ }^{\circ} \mathrm{C}$ may be attributed to the presence of $\mathrm{Nd}^{3+}$ ions in the interstitials or segregation of $\mathrm{Nd}$-oxide/hydroxide on the surface of $\mathrm{TiO}_{2}$. Enhanced atomic/ionic diffusion with increased heat treatment temperature and increased dopant concentration may increase the probability for the formation of Nd-oxide phases or $\mathrm{Nd}$-Ti-oxide phases. Mohammadi and Fray (2010) [54] prepared Nd-Ti oxide with 1:3 Nd:Ti molar ratio with particulate sol-gel method and found that $\mathrm{Nd}_{4} \mathrm{Ti}_{9} \mathrm{O}_{24}$ and $\mathrm{Nd}_{2} \mathrm{Ti}_{4} \mathrm{O}_{11}$ phases were formed in the $800-1000{ }^{\circ} \mathrm{C}$ temperature range. The molar ratio of $\mathrm{Nd}$ :Ti was 2:9 in $10 \% \mathrm{Nd}$ doped $\mathrm{TiO}_{2}$ powder prepared for this study.

$\mathrm{Nd}_{4} \mathrm{Ti}_{9} \mathrm{O}_{24}$ phase was formed above $0.25 \%$ doping level at $900{ }^{\circ} \mathrm{C}$ with small contribution of $\mathrm{Nd}_{2} \mathrm{Ti}_{4} \mathrm{O}_{11}$ phase (above $0.5 \%$ ). Anatase peak intensity increased up to $1 \%$ doping level and decreased beyond this doping level. The formation of a mixed oxide phase $\left(\mathrm{Nd}_{4} \mathrm{Ti}_{9} \mathrm{O}_{24}\right.$ or $\left.\mathrm{Nd}_{2} \mathrm{Ti}_{4} \mathrm{O}_{11}\right)$ rather than a single phase of $\mathrm{Nd}\left(\mathrm{Nd}_{2} \mathrm{O}_{3}\right)$ at $10 \%$ doping level was observed at $800{ }^{\circ} \mathrm{C}$. The formation of these phases beyond $0.25 \%$ and the decrease in the anatase peak intensity beyond $1 \%$ at $900{ }^{\circ} \mathrm{C}$ may be an indication an interstitial accommodation of $\mathrm{Nd}^{3+}$ ions along with the presence of a solubility limit of $\sim 0.5-1 \%$ in the $\mathrm{TiO}_{2}$ lattice. The decreased anatase peak intensities also may be an indication of the formation of $\mathrm{Nd}-\mathrm{Ti}-\mathrm{O}$ phases by the consumption of anatase crystallites.

XRD patterns of Er doped $\mathrm{TiO}_{2}$ powders heat treated in the $600-1000{ }^{\circ} \mathrm{C}$ temperature range are given in Fig. 4. Anatase was found to be the main phase in all Er doped $\mathrm{TiO}_{2}$ powders between 600 and $800{ }^{\circ} \mathrm{C}$ similar to $\mathrm{Nd}$ doped $\mathrm{TiO}_{2}$ powders. Rutile was detected at low doping levels at $700{ }^{\circ} \mathrm{C}$ and $800{ }^{\circ} \mathrm{C}$. Erbium titanate $\left(\mathrm{Er}_{2} \mathrm{Ti}_{2} \mathrm{O}_{7}\right)$ phase was determined to form at doping levels higher than $1 \%$ at $800{ }^{\circ} \mathrm{C}$ contrary to $\mathrm{Nd}$ doped $\mathrm{TiO}_{2}$ powders where only anatase crystallites were observed at these doping levels and heat treatment temperature. Anatase to rutile phase transformation kinetics was also affected by Er doping level. Anatase phase was observed even at $900{ }^{\circ} \mathrm{C}$ at $3-5 \%$ doping levels. Rutile and $\mathrm{Er}_{2} \mathrm{Ti}_{2} \mathrm{O}_{7}$ phases were the dominant phases at 900 and $1000^{\circ} \mathrm{C}$. A mixture of anatase-rutile- $\mathrm{Er}_{2} \mathrm{Ti}_{2} \mathrm{O}_{7}$ phases was detected beyond $0.25 \%$ doping level at $900{ }^{\circ} \mathrm{C}$.

Rutile and $\mathrm{Er}_{2} \mathrm{Ti}_{2} \mathrm{O}_{7}$ phases dominate the microstructure at $1000^{\circ} \mathrm{C}$ and the major anatase phase peaks were absent in the XRD 

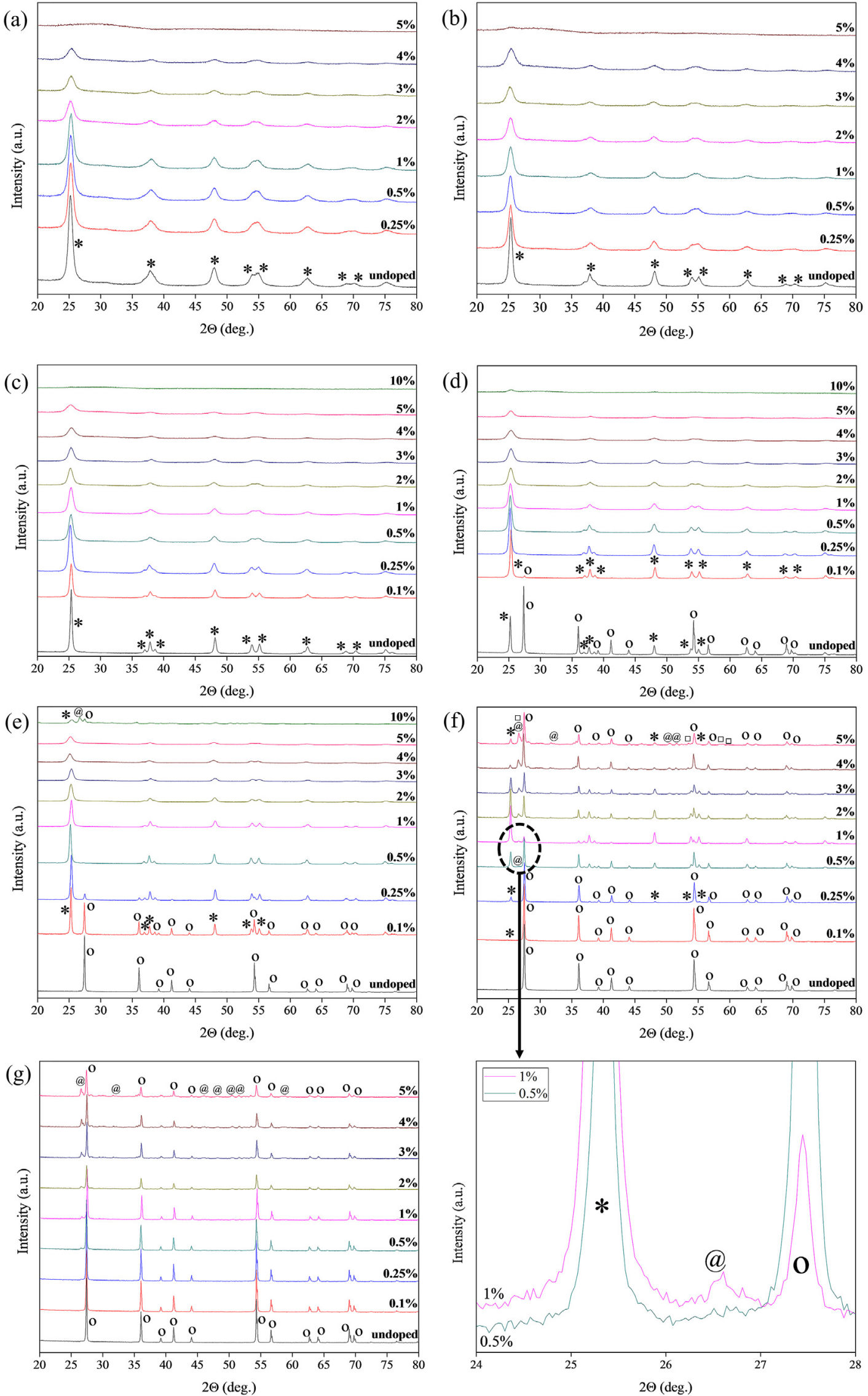

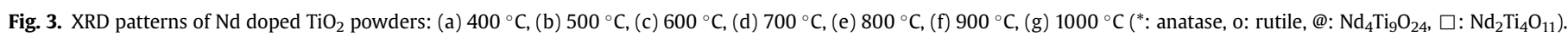



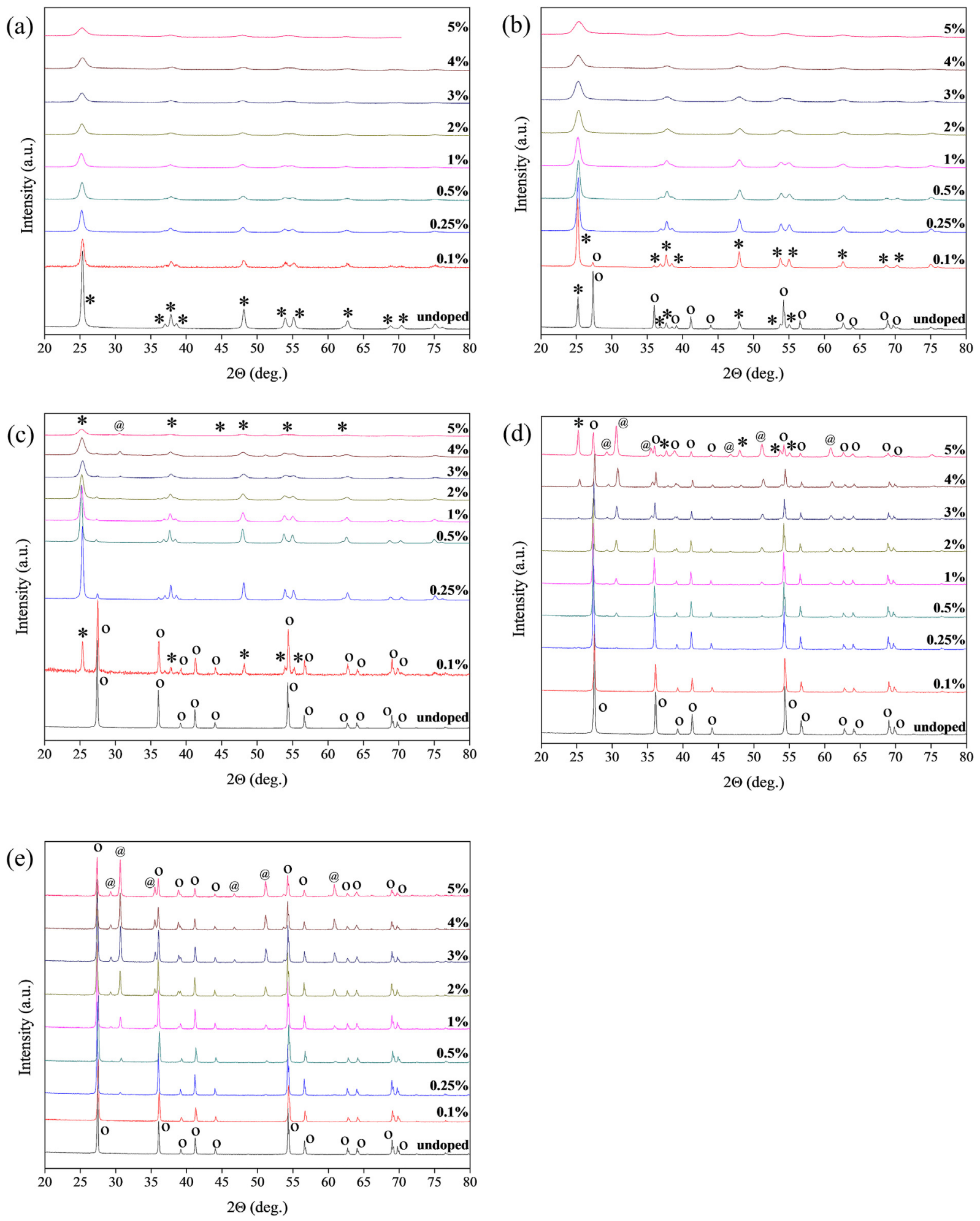

Fig. 4. XRD patterns of Er doped $\mathrm{TiO}_{2}$ powders: (a) $600{ }^{\circ} \mathrm{C}$, (b) $700{ }^{\circ} \mathrm{C}$, (c) $800{ }^{\circ} \mathrm{C}$, (d) $900{ }^{\circ} \mathrm{C}$, (e) $1000{ }^{\circ} \mathrm{C}\left({ }^{*}\right.$ : anatase, o: rutile, @: Er $\left.\mathrm{Ti}_{2} \mathrm{O}_{7}\right)$.

patterns of the powders. $\mathrm{RE}_{2} \mathrm{Ti}_{2} \mathrm{O}_{7}$ phase rather than $\mathrm{RE}_{4} \mathrm{Ti}_{9} \mathrm{O}_{24}$ phase was formed by Er doping unlike Nd doping. The relatively large ionic radii of the RE ions may restrict atomic mobility at low temperatures. The RE ion atomic mobility increases at elevated heat treatment temperatures causing the formation of RETiO and RE oxide phases to form at high doping levels.

$\mathrm{Er}_{2} \mathrm{Ti}_{2} \mathrm{O}_{7}$ phase was formed above $1 \%$ doping level at $800{ }^{\circ} \mathrm{C}$ whereas the formation of $\mathrm{Nd}_{4} \mathrm{Ti}_{9} \mathrm{O}_{24}$ phase was observed above $5 \%$ $\mathrm{Nd}$ doping level. The enhanced atomic mobility of the smaller $\mathrm{Er}^{3+}$ ion (103 p.m.) compared to the $\mathrm{Nd}^{3+}$ ion (112 p.m.) may be responsible for the formation of ErTiO phases at such lower doping levels.

According to Borlaf et al. (2013) [46] $\mathrm{Er}_{2} \mathrm{Ti}_{2} \mathrm{O}_{7}$ pyrochlore forms from rutile. Reflections of anatase phase began to appear at $3 \% \mathrm{Er}$ 
doping level at $900{ }^{\circ} \mathrm{C}$. Anatase to rutile phase transformation is known to be reconstructive involving the breaking and reforming of bonds [40] and can be inhibited by the surrounding RE ions in $\mathrm{TiO}_{2}$ grain boundaries or intersititial Er ions in the $\mathrm{TiO}_{2}$ lattice. The diffusion of interstitial $\mathrm{Er}^{3+}$ ions to the surface of the anatase crystallites may form $\mathrm{Er}_{2} \mathrm{Ti}_{2} \mathrm{O}_{7}$ in the nucleated rutile. Rutile phase content/ crystallite size decreased and $\mathrm{Er}_{2} \mathrm{Ti}_{2} \mathrm{O}_{7}$ phase content increased with Er doping level as can be seen from Figs. $4 \mathrm{~d}$ and $5 \mathrm{~b}$. The ionic radius, RE electropositivity and the coordination number decreases with increasing atomic number. This phenomenon leads to the formation of RETiO phases with lower coordination numbers [32].

The variation of anatase content and the anatase:rutile ratio with heat treatment temperature and $\mathrm{Nd} / \mathrm{Er}$ doping level are given in Fig. 5. Anatase weight fraction vs. heat treatment temperature curve shifted significantly to higher temperatures with increasing $\mathrm{Nd}$ doping level. The onset temperature for the complete transformation of anatase to rutile phase shifts from $700-800{ }^{\circ} \mathrm{C}$ to $800-900{ }^{\circ} \mathrm{C}$ temperature range by $\mathrm{RE}$ doping of titania beginning from $0.5 \%$ doping level. It may be interpreted as the onset of the transition temperature shifts to higher temperatures with RE doping level considering Fig. 5a. This behavior indicated that the evolution of anatase to rutile may be retarded and the nanodesign of the phase structure may be achieved by adjusting $\mathrm{Nd}$ doping level and heat treatment temperature.

This nanodesign can also be achieved by using different RE ions. The use of $\mathrm{Er}^{3+}$ ion instead of $\mathrm{Nd}^{3+}$ ion at the same doping level may also affect the anatase content of the powder as can be seen in Fig. 5a. The use of $\mathrm{Nd}^{3+}$ ion has a more inhibitory effect on anatase to rutile phase transformation as compared to $\mathrm{Er}^{3+}$ ion. Fig. $5 \mathrm{~b}$ indicates that the inhibition of anatase to rutile phase transformation becomes significant at higher Er doping levels compared to $\mathrm{Nd}$.

The variation of the anatase:rutile ratio with $\mathrm{Nd}$ doping level shown in Fig. $5 \mathrm{~b}$ indicated that the formation of $\mathrm{Nd}_{4} \mathrm{Ti}_{9} \mathrm{O}_{24}$ phase (see also Fig. 3 where the formation of this NdTiO phase starts at $0.5-1 \%$ doping level at $900{ }^{\circ} \mathrm{C}$ ) may be reconstructive which involves the $\mathrm{Ti}-\mathrm{O}$ bond breakage and $\mathrm{Nd}-\mathrm{Ti}-\mathrm{O}$ bond formation. $\mathrm{Er}_{2} \mathrm{Ti}_{2} \mathrm{O}_{7}$ pyrochlore forms from rutile according to Borlaf et al. (2013) [46]. The XRD patterns of Er doped $\mathrm{TiO}_{2}$ powders heat treated at $900-1000{ }^{\circ} \mathrm{C}$ in this work indicate that the intensities of the rutile peaks decreased while that of the $\mathrm{Er}_{2} \mathrm{Ti}_{2} \mathrm{O}_{7}$ phase increased. This may be due to rutile phase grain growth inhibition and $\mathrm{Er}_{2} \mathrm{Ti}_{2} \mathrm{O}_{7}$ phase formation through the consumption of rutile crystallites.

Anatase crystallite sizes determined by using XRD patterns of $\mathrm{Nd} /$ Er doped $\mathrm{TiO}_{2}$ powders and equation (1) are given in Fig. 6. The crystallite sizes increased with increasing heat treatment temperature and decreased with increasing doping level. The variation of crystallite size is more significant at low doping levels (up to 1\%). The crystallite sizes are similar $(\sim 10 \mathrm{~nm})$ above $1 \%$ doping level for all heat treatment temperatures. The crystallite sizes of Nd doped $\mathrm{TiO}_{2}$ powders are generally lower than that of $\mathrm{Er}$ doped $\mathrm{TiO}_{2}$ powders which may indicate that larger $\mathrm{RE}$ ion $\left(\mathrm{Nd}^{3+}\right)$ is more effective on the anatase to rutile phase transformation inhibition.

Anatase lattice constants $\boldsymbol{a}$ and $\boldsymbol{c}$ of $\mathrm{Nd} / \mathrm{Er}$ doped $\mathrm{TiO}_{2}$ powders heat treated at $700{ }^{\circ} \mathrm{C}$ and anatase lattice constant $\boldsymbol{c}$ of Nd doped $\mathrm{TiO}_{2}$ powders heat treated in the $400-700{ }^{\circ} \mathrm{C}$ temperature range
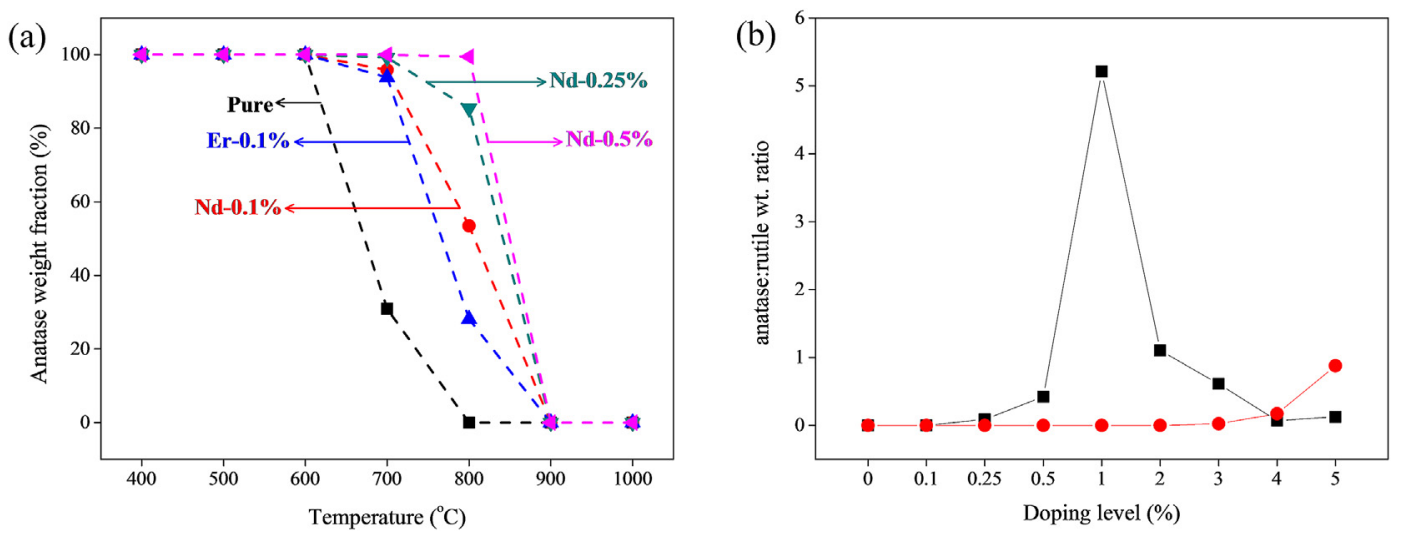

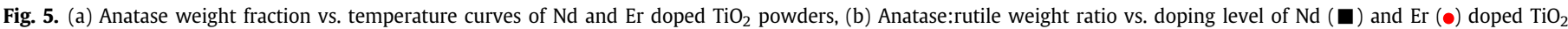
powders heat treated at $900{ }^{\circ} \mathrm{C}$.
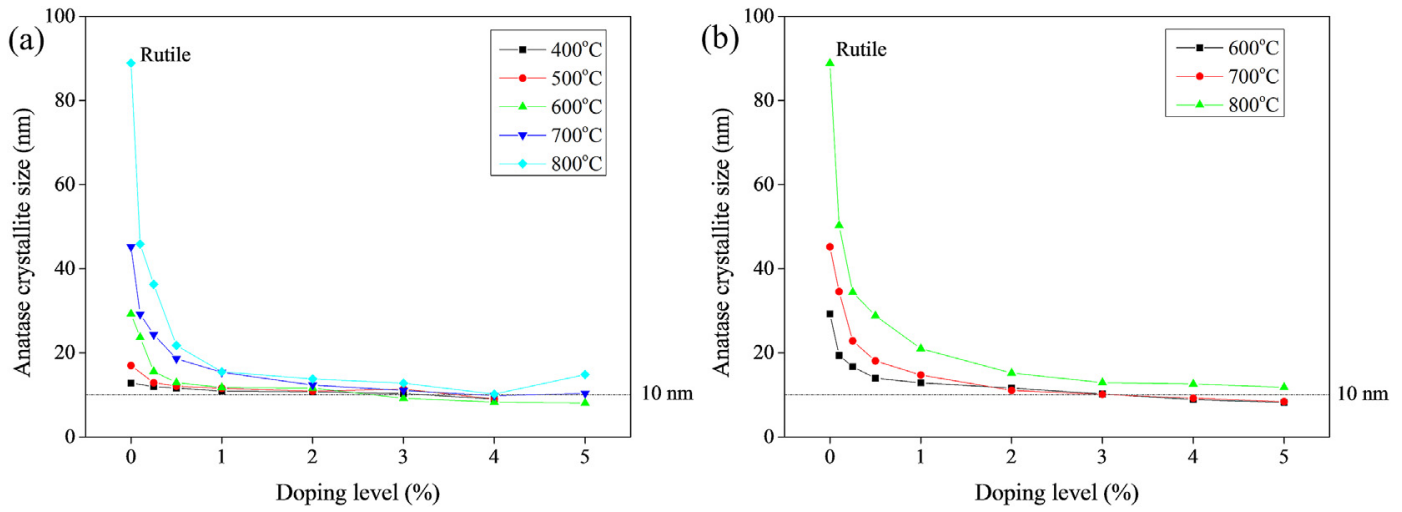

Fig. 6. Anatase crystallite sizes of (a) $\mathrm{Nd}$ and (b) $\mathrm{Er}$ doped $\mathrm{TiO}_{2}$ powders heat treated in the $600-800{ }^{\circ} \mathrm{C}$ temperature range. 

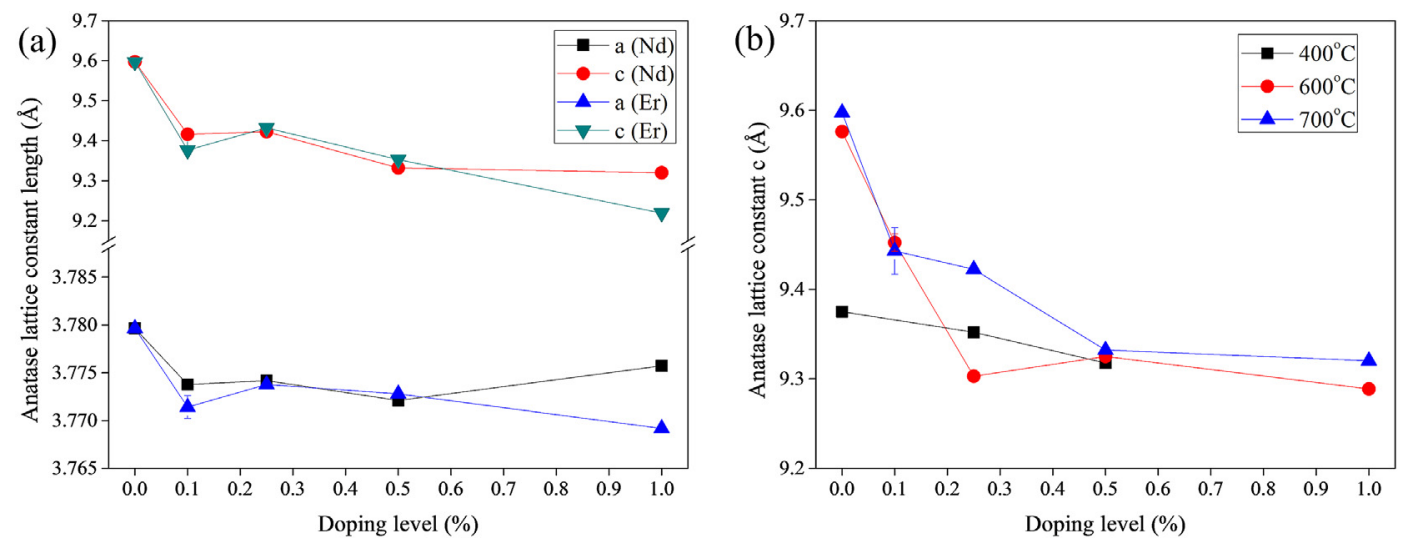

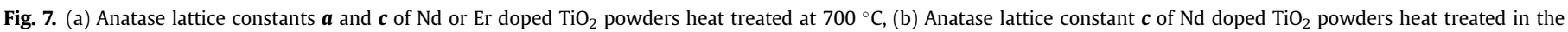
$400-700{ }^{\circ} \mathrm{C}$ temperature range.

are given in Fig. 7. Anatase lattice constant $\boldsymbol{a}$ slightly decreased where as $\boldsymbol{c}$ significantly decreased with increasing doping level. The decrease in the lattice constants may be due to the decrease in the crystallite size as was previously stated in the literature [55] or the presence of oxygen vacancies in the nanostructure. These findings indicated a possible segregation of $\mathrm{Nd} / \mathrm{Er}$ oxides/hydroxides on the grain boundaries or intersititial accommodation of $\mathrm{Nd} / \mathrm{Er}^{3+}$ ions in the $\mathrm{TiO}_{2}$ lattice. As discussed in the phase analysis of $\mathrm{Nd} / \mathrm{Er}$ doped $\mathrm{TiO}_{2}$ powders, the more electropositivity of segregated RE ions on the grain boundaries and the attraction of lattice oxygen which may form oxygen deficiencies in the $\mathrm{TiO}_{2}$ lattice may cause contraction. According to Wang et al. (2010) [12] $\mathrm{Nd}^{3+}$ ions can form bond with non-bridging oxygen ion in the surroundings of $-\mathrm{Ti}-\mathrm{O}-\mathrm{Ti}-\mathrm{O}-$ network structure. $\mathrm{O}^{2-}$ ions would be expelled from the lattice when a RE ion accommodates on the grain boundaries and attract oxygen. Lattice contracts along $\mathrm{c}$ axis due to $\mathrm{O}^{2-}$ ion migration with a larger ionic radius (132 p.m.) than $\mathrm{RE}$ or $\mathrm{Ti}^{4+}$ ion. The decrease in the crystallite size of the $\mathrm{TiO}_{2}$ nanoparticles with increasing RE doping level may be the main cause in the lattice contraction and strain.

Anatase lattice strain of $\mathrm{Nd} / \mathrm{Er}$ doped $\mathrm{TiO}_{2}$ powders are given in Fig. 8. Lattice strain increases continuously with doping level at $500^{\circ} \mathrm{C}$ and $600^{\circ} \mathrm{C}$, however the presence of rutile phase (even trace amounts at $1 \%$ Er doping level) at $700{ }^{\circ} \mathrm{C}$ significantly affected the

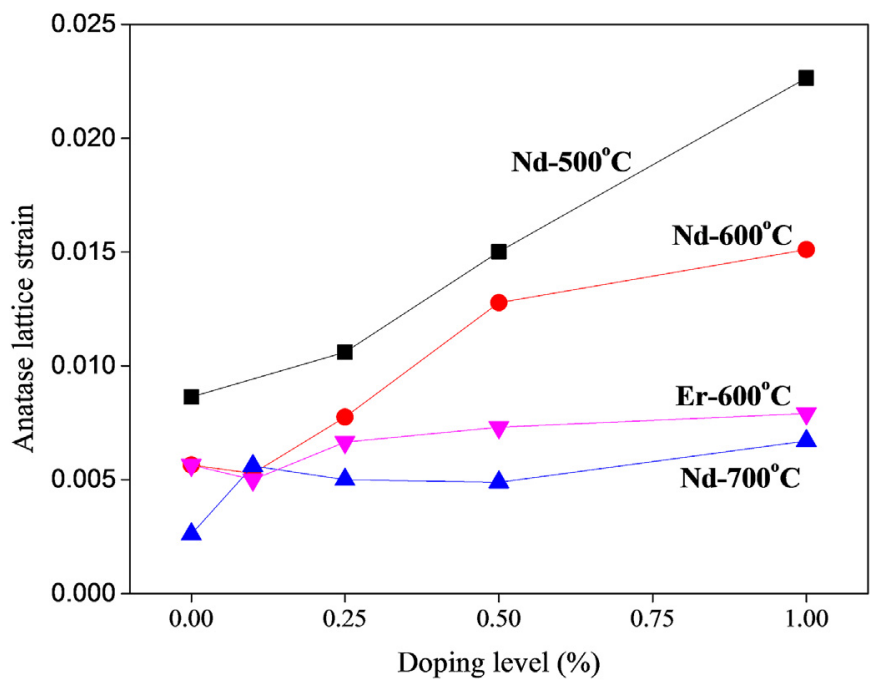

Fig. 8. Anatase lattice strain of $\mathrm{Nd} / \mathrm{Er}$ doped $\mathrm{TiO}_{2}$ powders heat treated in the $500-700{ }^{\circ} \mathrm{C}$ temperature range. strain in the microstructure. Lattice strain in rutile particles are less compared to anatase particles since rutile is more stable and has a more ordered structure. Powders heat treated at $500{ }^{\circ} \mathrm{C}$ exhibit higher lattice strain and strain decreases with heat treatment temperature. The high lattice strain at $500{ }^{\circ} \mathrm{C}$ may be due to excess number of disordered atoms and defects on the grain boundaries. These atoms and defects cause a stress field (surface strain). Lattice strain of all the powders are positive indicating a tensile strain. Tensile strain can be induced by a decrease in crystallite size. Crystallite size decreases with increasing doping level and lattice strain increases. The effect of crystallite size difference in $\mathrm{Nd}$ and $\mathrm{Er}$ doped $\mathrm{TiO}_{2}$ powders on the lattice strain can be seen in Fig. 8. The strain in Nd doped powders increase more significantly compared to Er doped powders since the crystallite sizes of Nd doped powders are smaller and particles are subjected to more surface strain. Oxygen deficiencies may induce lattice strain in the structure [56]. The increase in the lattice strain may be a result of both crystallite size decrease and introduced oxygen deficiencies. Defects on the grain boundaries can partially be reduced by increasing the heat treatment temperature causing a decrease in the lattice strain. The strain decreases with increasing heat treatment temperature for both undoped and Nd doped $\mathrm{TiO}_{2}$ powders as shown in Fig. 8 .

Nitrogen adsorption-desorption isotherms and Brunauer-Emmett-Teller (BET) surface areas of selected Nd/Er doped $\mathrm{TiO}_{2}$ powders heat treated at $700{ }^{\circ} \mathrm{C}$ are given in Fig. 9. The isotherms are of Type IV (Brunauer-Demig-Demign-Teller, BDDT, classification) with a hysteresis loop (H3) which is typical for mesoporous materials. This type of isotherm is an indication of mesoporous structure with high adsorption energies and formation of narrow slit-like pores. This structure was observed in all doped $\mathrm{TiO}_{2}$ powders unlike undoped $\mathrm{TiO}_{2}$ with relatively large pores (average pore diameters: $12.9 \mathrm{~nm}$, pore volume: $0.00804 \mathrm{~cm}^{3} / \mathrm{g}$ ) formed by sintered grains (supported by TEM) which also leads to a decrease in the surface area. $\mathrm{Nd} / \mathrm{Er}$ doping as can be seen from Fig. 9e significantly affect the powder surface area. The surface area was increased up to 35 folds by Er/Nd doping at $700{ }^{\circ} \mathrm{C}$. Increased thermal stability with decreased crystallite sizes achieved by RE doping increases the surface area. The surface area however starts decreasing above a doping level of $2 \%$ which may be due to the grain growth of the RE containing secondary phases along the grain boundaries of $\mathrm{TiO}_{2}$ phases decreasing the $\mathrm{N}_{2}$ accessibility of the nanostructure.

\subsection{XPS analysis of $\mathrm{Nd} / \mathrm{Er}$ doped $\mathrm{TiO}_{2}$ powders}

The XPS spectra of Nd/Er undoped/doped $\mathrm{TiO}_{2}$ powders heat 

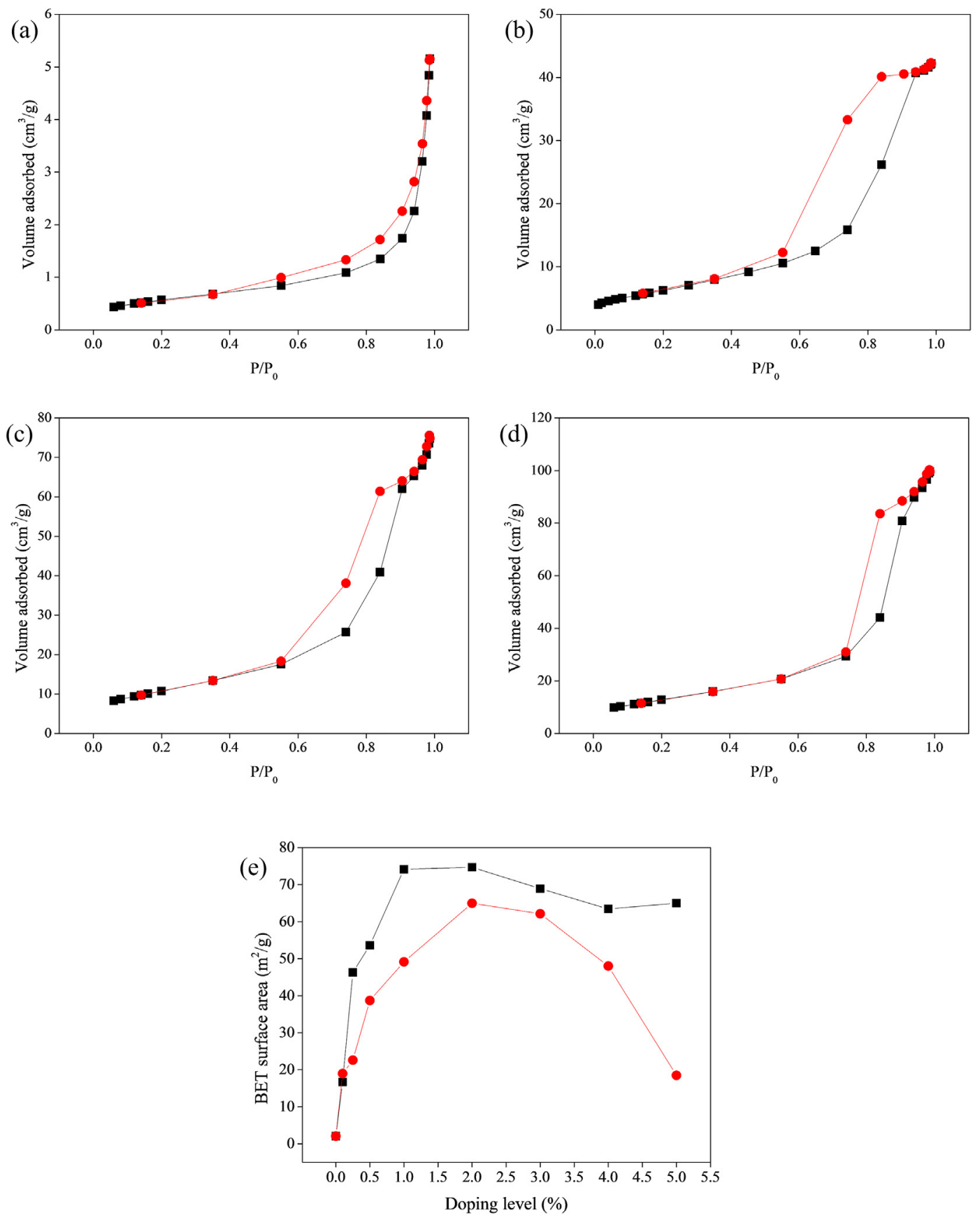

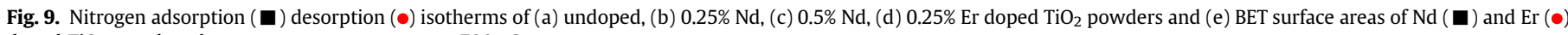
doped $\mathrm{TiO}_{2}$ powders, heat treatment temperature: $700{ }^{\circ} \mathrm{C}$.

treated at $700{ }^{\circ} \mathrm{C}$ are given in Fig. 10. Ti2p core level spectrum is formed from Ti2 $\mathrm{p}_{1 / 2}$ and $\mathrm{Ti} 2 \mathrm{p}_{3 / 2}$ peaks. The Ti2 $\mathrm{p}_{1 / 2}$ and Ti2 $\mathrm{p}_{3 / 2}$ spinorbital splitting photoelectrons for all powders are located at binding energies of approximately 465.2 and $459.3 \mathrm{eV}$, respectively. The difference between these two lines is about $5.9 \mathrm{eV}$ which showed that the oxidation state of titanium is mostly $\mathrm{Ti}^{4+}$ in the prepared powders. 01s peak appearing at $529 \mathrm{eV}$ is attributed to the signal of oxygen in $\mathrm{TiO}_{2}$ lattice. Shoulder appearing at $531.5 \mathrm{eV}$ is the signal of oxygen in $\mathrm{Ti}-\mathrm{OH}$ or $\mathrm{C}-\mathrm{OH}$. The intensity of this peak decreases with $\mathrm{Nd}$ doping level, preserving its existence. Carbon residuals exist in undoped $\mathrm{TiO}_{2}$ since it consists of sintered grains resulting in a closed pore structure limiting the removal of carbonaceous species which may form $\mathrm{C}-\mathrm{OH}$ bonds on the grain boundaries.

The O:Ti atomic ratios and $\mathrm{Ti} 2 \mathrm{p}_{3 / 2}$ binding energies calculated from the XPS spectra are given in Fig. 11. Ti2 $\mathrm{p}_{3 / 2}$ binding energies shifted towards lower energies in $\mathrm{Nd} / \mathrm{Er}$ doped powders compared to the undoped powder. The $\mathrm{Ti}_{2} \mathrm{p}_{3 / 2}$ binding energies of doped powders are lower than that of undoped powders. The binding energies in $\mathrm{Er}$ doped powders are also lower than $\mathrm{Nd}$ doped powders. The decrease in $\mathrm{Ti}_{2} \mathrm{p}_{3 / 2}$ binding energies may be attributed to $\mathrm{Ti}^{4+}$ and $\mathrm{O}^{2-}$ local environment change by the introduction of Nd or Er atoms. This shift may also be attributed to the formation of $\mathrm{Ti}-\mathrm{Nd}$ bonds on the grain boundaries of the crystallites reducing the $\mathrm{Ti}^{4+}$ binding energy. The XPS spectra given in Fig. 10c and $\mathrm{d}$ indicate the increasing $\mathrm{Nd} 3 \mathrm{~d}$ and $\mathrm{Er} 4 \mathrm{~d}$ peak intensities with 


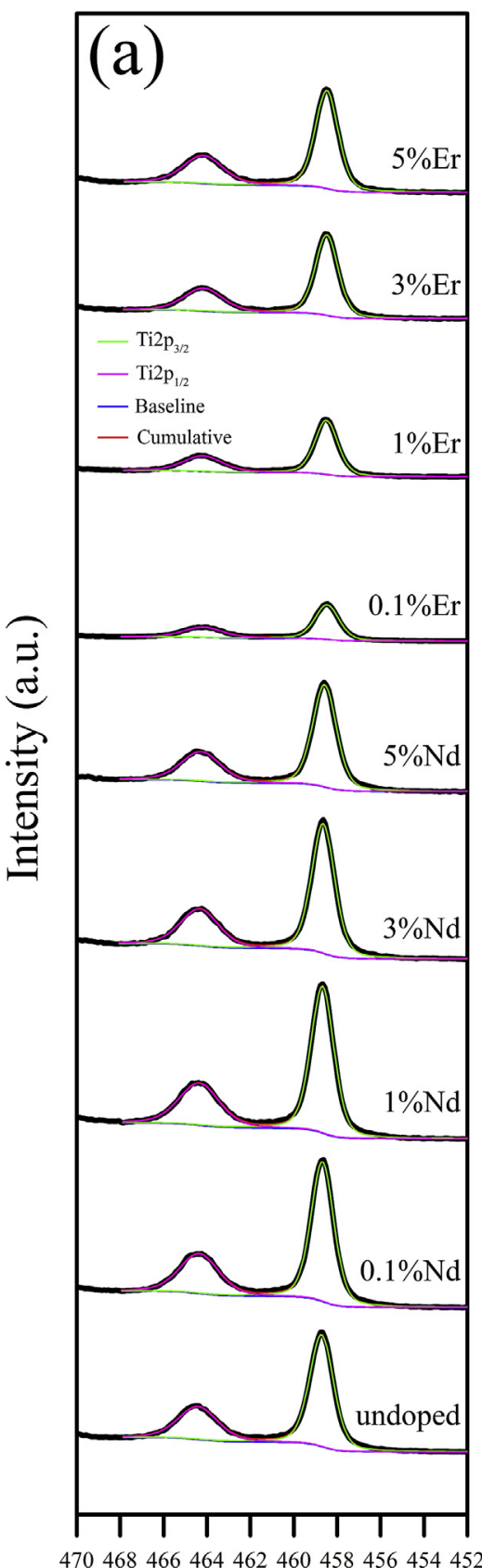

Binding energy $(\mathrm{eV})$

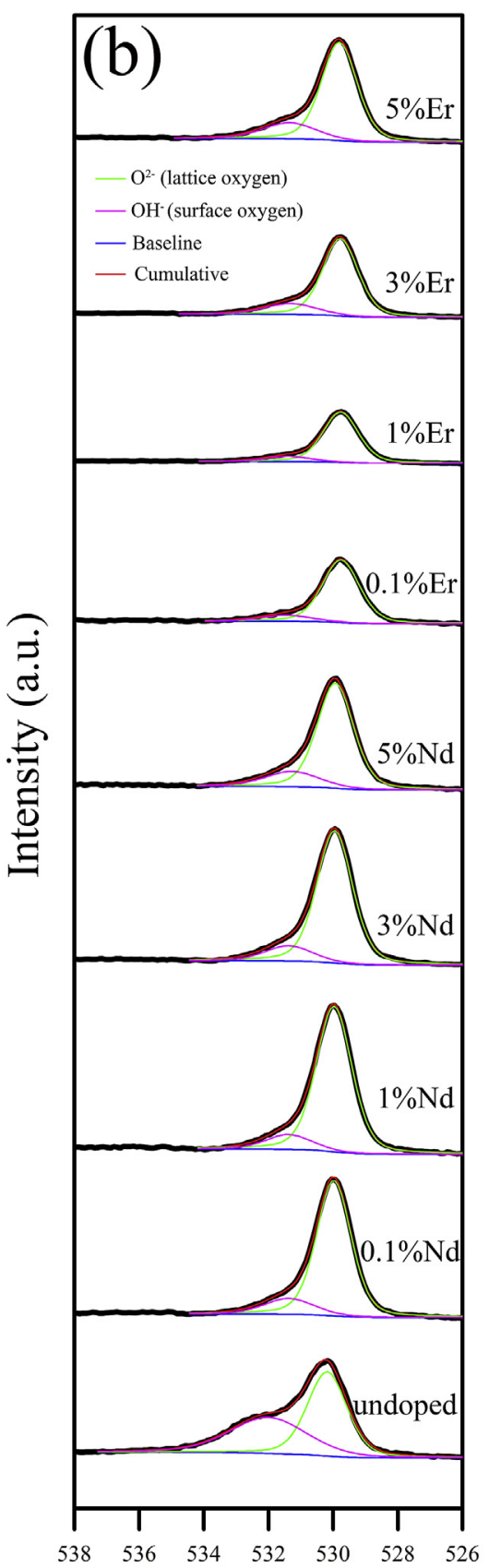

Binding energy $(\mathrm{eV})$

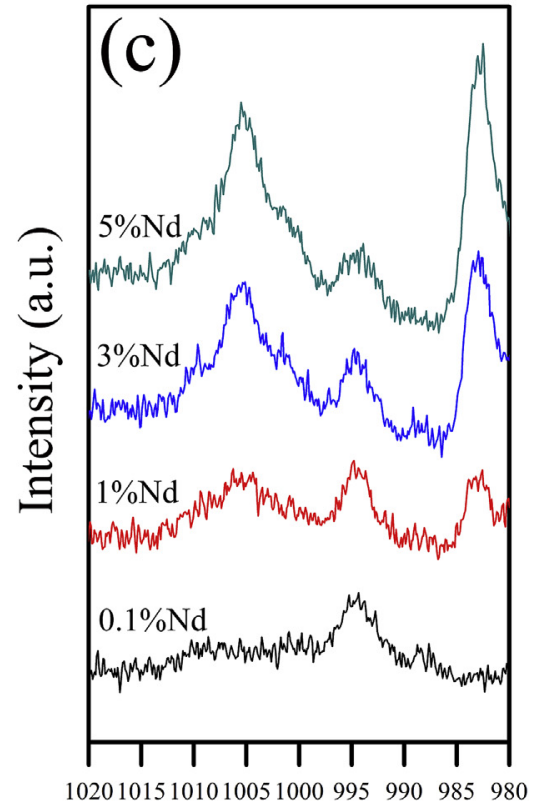

Binding energy $(\mathrm{eV})$

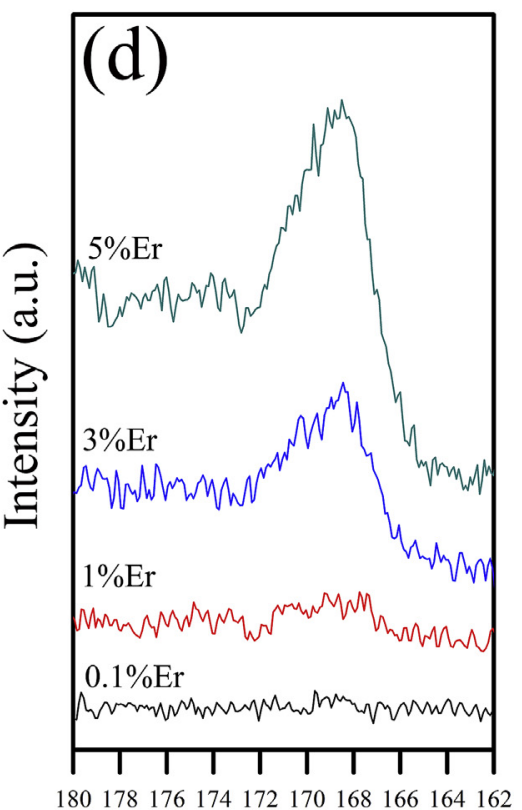

Binding energy $(\mathrm{eV})$

Fig. 10. (a) Ti2p, (b) O1s, (c) Nd3d and (d) Er4d XPS spectra of $\mathrm{Nd} / \mathrm{Er}$ undoped/doped $\mathrm{TiO}_{2}$ powders heat treated at $700{ }^{\circ} \mathrm{C}$.

increasing doping level in the powders.

The O:Ti ratio in the undoped powder was found to be significantly lower than theoretical ratio of 2 . This is mainly due to the entrapped substitutional carbon atoms $\left(\mathrm{C}^{4+}: 30\right.$ p.m., $\mathrm{Ti}^{4+}: 68$ p.m. $)$ in the lattice structure. The O:Ti atomic ratios in the Nd/Er doped $\mathrm{TiO}_{2}$ powders were found to be higher than that of the undoped powder. The main reason in the increase of the O:Ti atomic ratio is the removal of most of the entrapped carbon from the lattice through the open pore structure due to the inhibited phase transformation/densification of the nanostructure caused by RE doping. The O:Ti atomic ratios in Nd doped powders are higher than that of Er doped powders. These results supported the reported fact that $\mathrm{Nd}^{3+}$ ions are more electropositive than $\mathrm{Er}^{3+}$ ions and $\mathrm{Nd}$ doping thus may create a more oxygen rich nanophase structure. The structure is also more open in Nd doped powders as was discussed in the previous section on surface areas creating an easier removal of carbon which may increase the O:Ti atomic ratio.

\subsection{HR-TEM analysis of $\mathrm{Nd} / \mathrm{Er}$ doped $\mathrm{TiO}_{2}$ powders}

The HR-TEM images of undoped, $\mathrm{Nd} / \mathrm{Er}$ doped $\mathrm{TiO}_{2}$ powders heat treated at $800{ }^{\circ} \mathrm{C}$ and $900{ }^{\circ} \mathrm{C}$ are given in Figs. 12-17. Interplanar spacing (d-spacing) values determined by measuring the lattice fringes are also given as yellow text below the corresponding planes given in HR-TEM images. HR-TEM analysis indicated that all phases of $\mathrm{TiO}_{2}$ and $\mathrm{RE}-\mathrm{Ti}$ oxides (anatase, rutile, $\mathrm{Er}_{2} \mathrm{Ti}_{2} \mathrm{O}_{7}$ and 


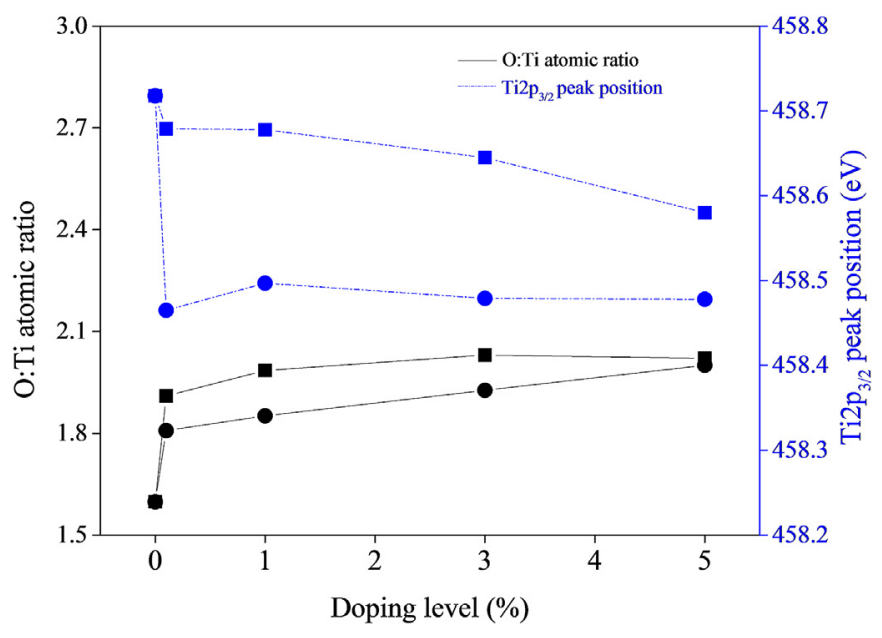

Fig. 11. O:Ti atomic ratios and $\mathrm{Ti}_{2} \mathrm{p}_{3 / 2}$ binding energies in $\mathrm{Nd} / \mathrm{Er}$ doped $\mathrm{TiO}_{2}$ powders

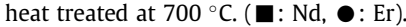

$\mathrm{Nd}_{4} \mathrm{Ti}_{9} \mathrm{O}_{24}$ ) detected in the XRD patterns were also identified in the corresponding HR-TEM images by using the lattice fringes and FFT images. Three different planes of rutile phase were identified in the undoped $\mathrm{TiO}_{2}$ powder heat treated at $900{ }^{\circ} \mathrm{C}$ as shown in Fig. 12 . These planes were (101), (220) and (110) with d-spacings of $0.25 \mathrm{~nm}, 0.16 \mathrm{~nm}$ and $0.32 \mathrm{~nm}$, respectively. The inset image at a lower magnification in the same figure indicates the presence of 100-200 nm crystallites which agrees reasonably well with XRD determined crystallite size of about $100 \mathrm{~nm}$. The (440), (111) and (222) planes of $\mathrm{Er}_{2} \mathrm{Ti}_{2} \mathrm{O}_{7}$ phase, the (101) anatase and the (110) rutile planes were identified in the HR-TEM image of 5\% Er doped
$\mathrm{TiO}_{2}$ powder heat treated at $900{ }^{\circ} \mathrm{C}$ as shown in Fig. 13 . The size of the $\mathrm{Er}_{2} \mathrm{Ti}_{2} \mathrm{O}_{7}$ crystallite was estimated to be about $40 \mathrm{~nm}$ which agrees reasonably well with XRD determined crystallite size of about $32 \mathrm{~nm}$. The (440) plane of $\mathrm{Nd}_{4} \mathrm{Ti}_{9} \mathrm{O}_{24}$ was identified with (101) anatase and (110) rutile planes in the HR-TEM image of $5 \% \mathrm{Nd}$ doped $\mathrm{TiO}_{2}$ powder heat treated at $900{ }^{\circ} \mathrm{C}$ as shown in Fig. 14. The inset image at a lower magnification in the same figure indicates the presence of $\sim 45 \mathrm{~nm}$ crystallites which agrees reasonably well with XRD determined crystallite sizes of about $45 \mathrm{~nm}$ for all the present three phases.

The HR-TEM images of 3\% Er doped $\mathrm{TiO}_{2}$ powder heat treated at $800{ }^{\circ} \mathrm{C}$ indicated a multiphase nanocrystalline structure formed from anatase, rutile and $\mathrm{Er}_{2} \mathrm{Ti}_{2} \mathrm{O}_{7}$ phases as shown in Fig. 15. The inset image at a lower magnification in the same figure indicates the presence of crystallites with sizes below $50 \mathrm{~nm}$ which agrees reasonably well with XRD determined crystallite sizes of $13 \mathrm{~nm}$, $40 \mathrm{~nm}$ and $22 \mathrm{~nm}$ for anatase, rutile and $\mathrm{Er}_{2} \mathrm{Ti}_{2} \mathrm{O}_{7}$ phases, respectively. The HR-TEM images of $3 \% \mathrm{Nd}$ doped $\mathrm{TiO}_{2}$ powder heat treated at $800{ }^{\circ} \mathrm{C}$ indicated a nanophase structure consisting of pure anatase crystallites as shown in Fig. 16. The inset image at a lower magnification in the same figure indicates the presence of crystallites with sizes below $20 \mathrm{~nm}$ which agrees reasonably well with XRD determined crystallite size of $14 \mathrm{~nm}$. The (440) plane of $\mathrm{Nd}_{4} \mathrm{Ti}_{9} \mathrm{O}_{24}$ phase was identified in the HR-TEM image for a higher doping level (10\%) with (101) anatase and (110) rutile planes as shown in Fig. 17. All the phases identified in the HR-TEM images were well correlated with the phases detected in the XRD patterns of the corresponding powders at the corresponding heat treatment temperatures and doping levels. $\mathrm{Er}_{2} \mathrm{O}_{3}$ and $\mathrm{Nd}_{2} \mathrm{O}_{3}$ contents of $5 \% \mathrm{Er}$ and $\mathrm{Nd}$ doped $\mathrm{TiO}_{2}$ powders heat treated at $900{ }^{\circ} \mathrm{C}$ were calculated as $5.8 \%$ and $5.3 \%$ (molar basis), respectively by using TEM-EDX which showed that intended composition of $5 \% \mathrm{RE}_{2} \mathrm{O}_{3}$ was achieved.

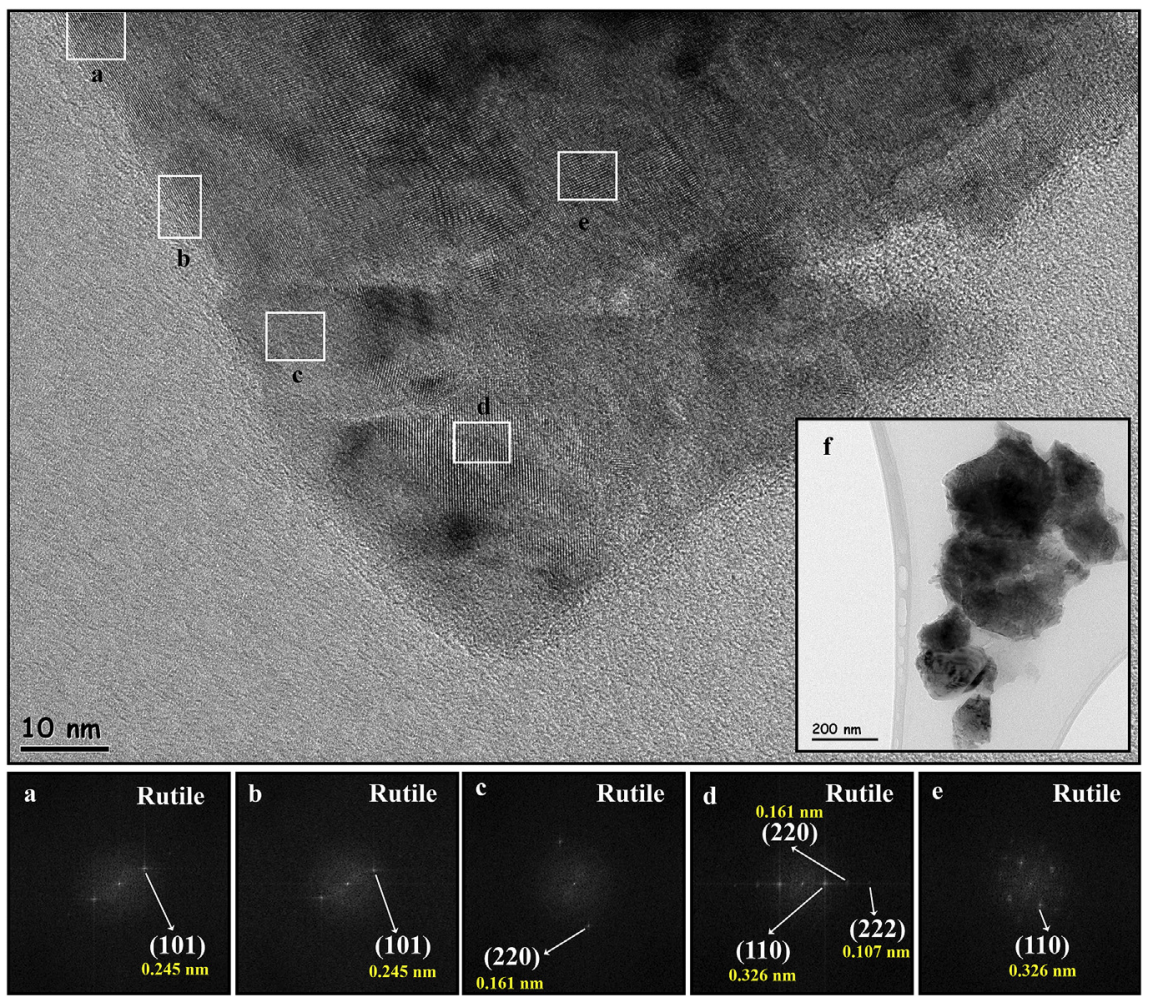

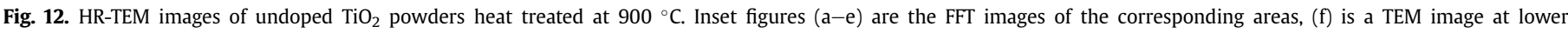
magnification. 


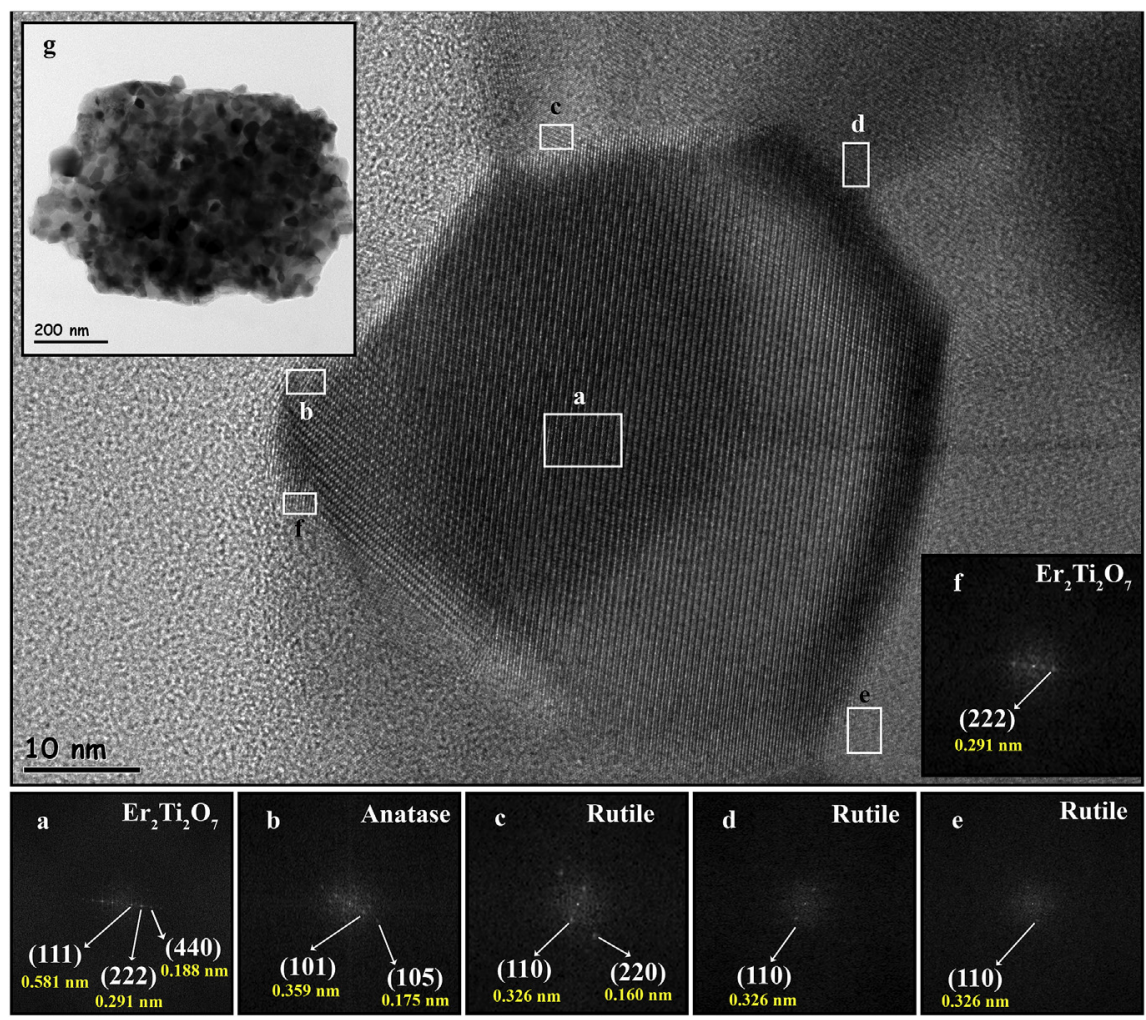

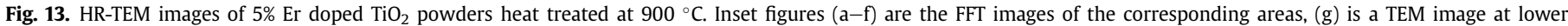
magnification.

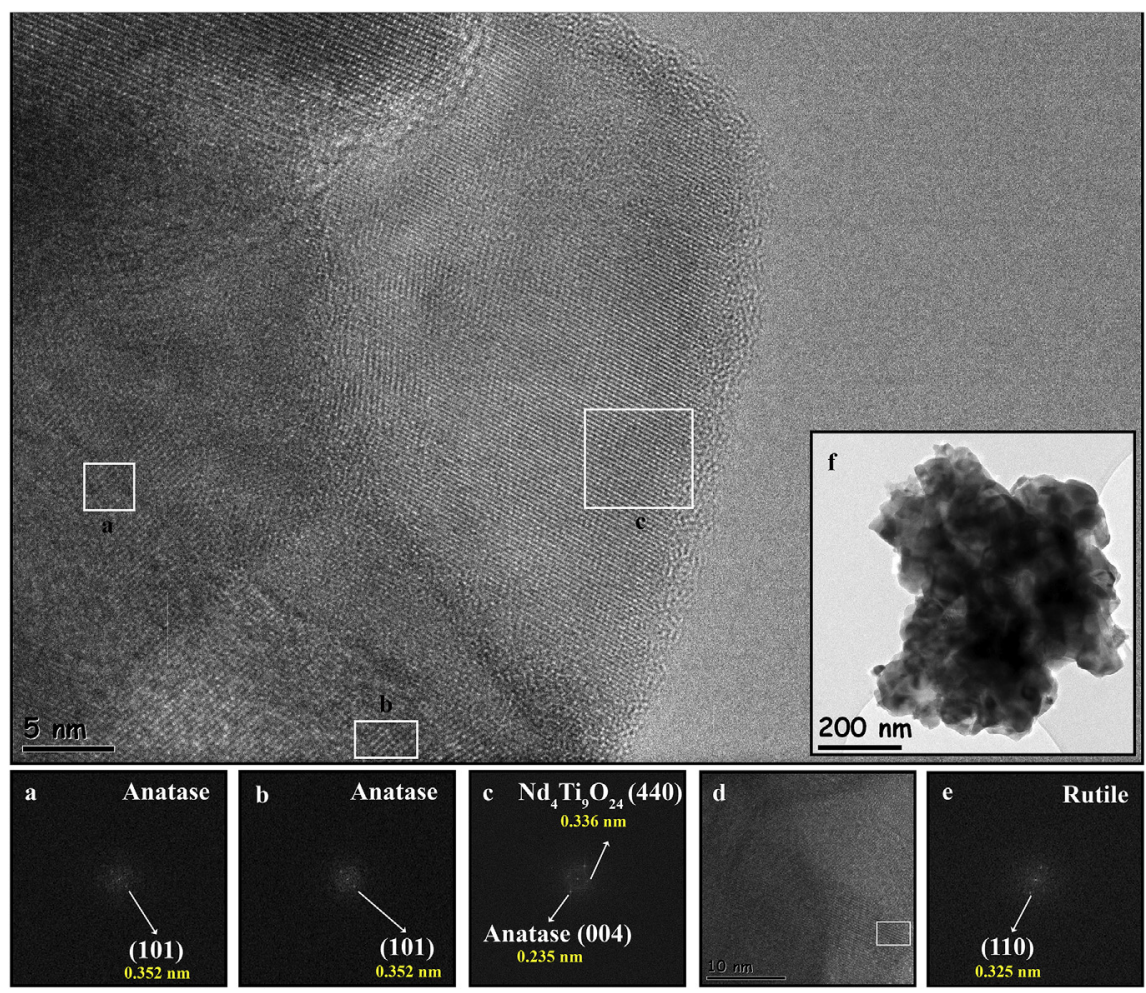

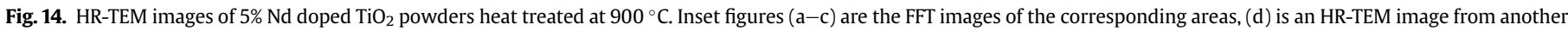
region, (e) is the FFT image of (d), (f) is a TEM image at lower magnification. 

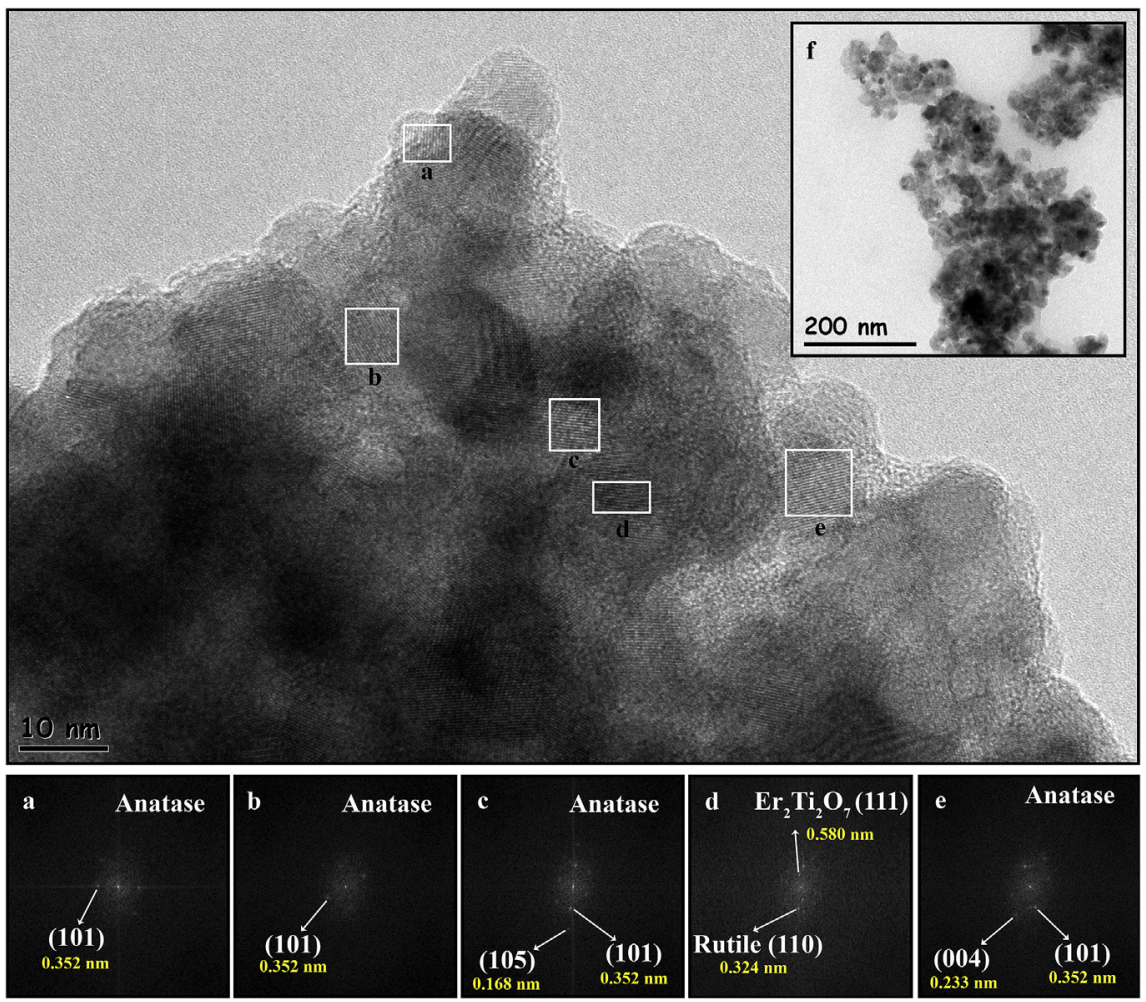

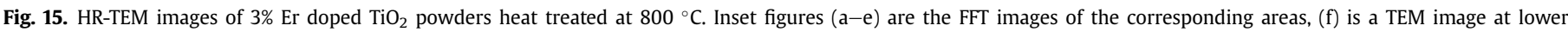
magnification.

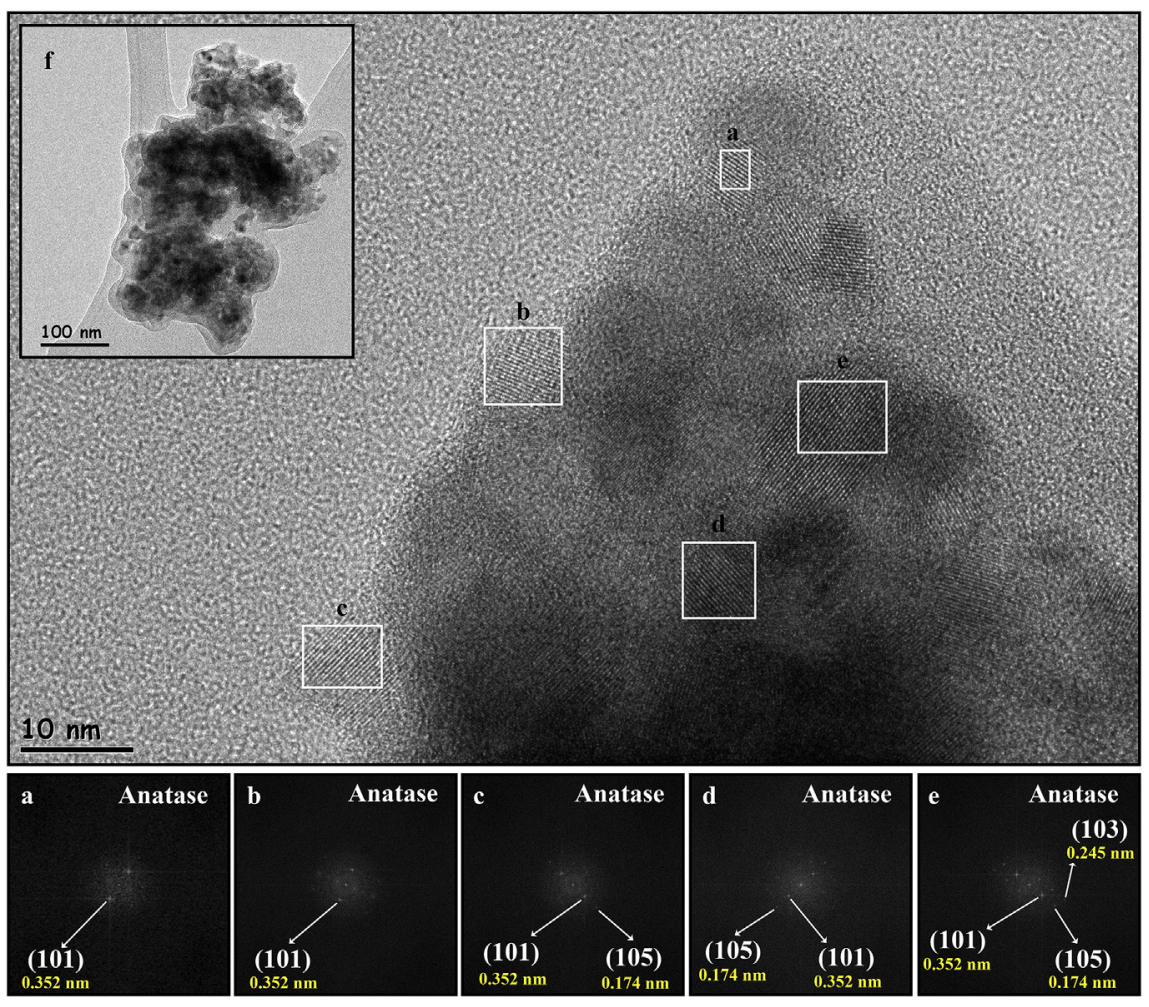

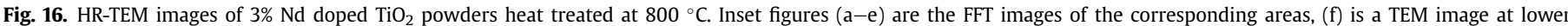
magnification. 


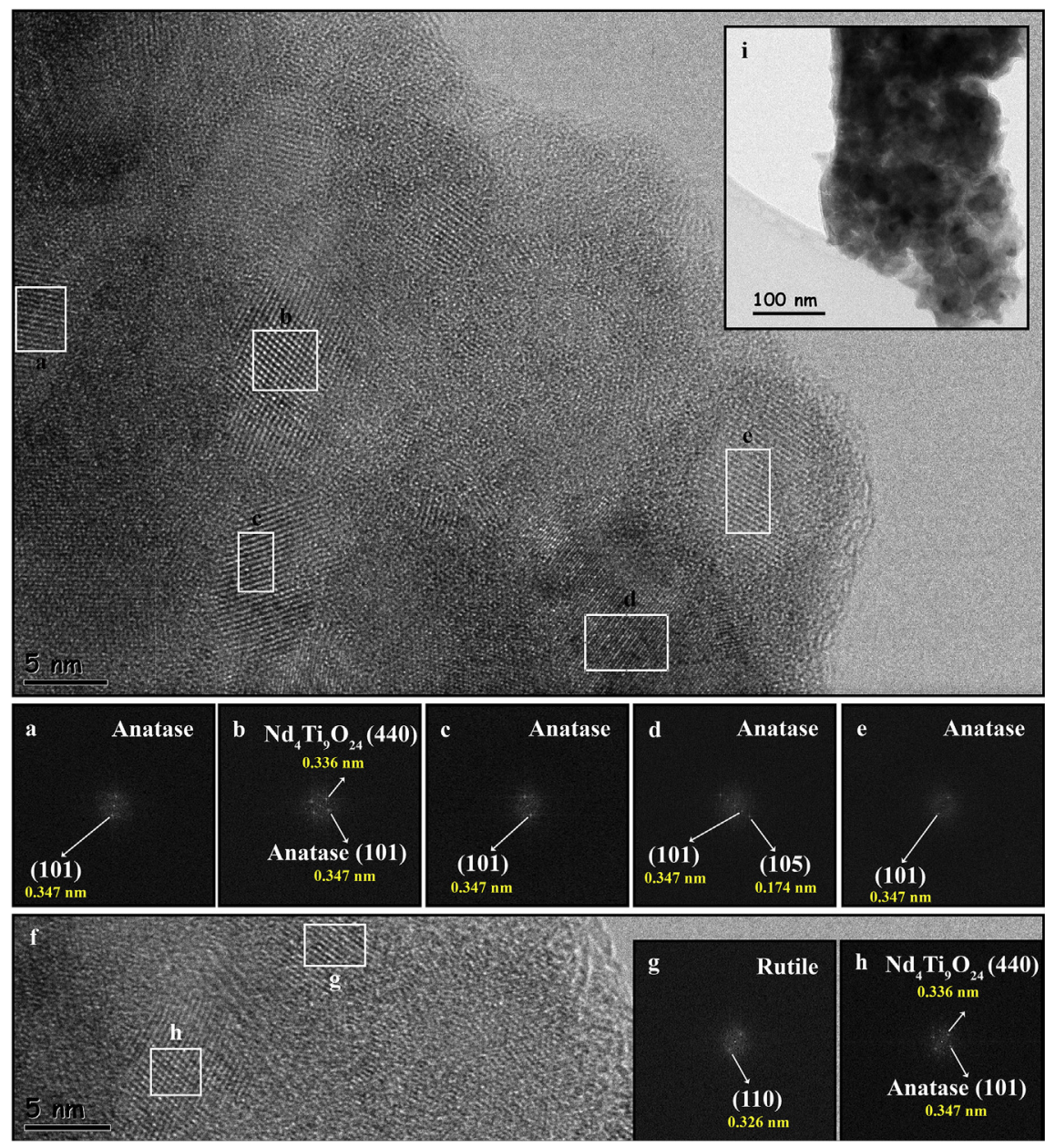

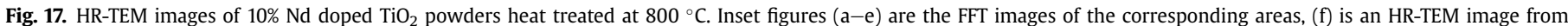
another region, (g) and (h) are the FFT images of the corresponding areas in (f), (i) is a TEM image at lower magnification.

\subsection{Phase structure of various $\mathrm{RES}$ doped $\mathrm{TiO}_{2}$ powders}

A series of other REs (La, Pr, Nd, Sm, Eu, Gd, Tb, Dy, Er Ce, Yb) were also used for doping $\mathrm{TiO}_{2}$ powders in order to investigate the effect of $\mathrm{RE}$ ionic radius on the nanostructure evolution of $\mathrm{TiO}_{2}$. The XRD patterns of $5 \% \mathrm{RE}$ doped $\mathrm{TiO}_{2}$ powders heat treated at $800{ }^{\circ} \mathrm{C}$ are shown in Fig. 18. The formation of $\mathrm{RE}_{2} \mathrm{Ti}_{2} \mathrm{O}_{7}$ phases (with similar reflections at $2 \Theta$ values of $\sim 30.6, \sim 29.3$ ) and $\mathrm{CeO}_{2}$ phase (with $2 \Theta$ of 28.5) were determined according to Joint Committee on Powder Diffraction Standards (JCPDS) cards of the corresponding phases. The formation of $\mathrm{RE}_{2} \mathrm{Ti}_{2} \mathrm{O}_{7}$ phases were detected for the RE elements with atomic numbers in the $63-70$ range $(\mathrm{Eu}-\mathrm{Yb}$ with $\mathrm{Yb}$ having the smallest ionic size in the RE elements with atomic numbers in the $57-70$ range). The absence of the $\mathrm{RE}_{4} \mathrm{Ti}_{9} \mathrm{O}_{24}$ phases shows that the solid state diffusion rate and dopant concentration level is not sufficient at this temperature and doping level for the formation of these phases. The ionic radii of REs vary between 117.2 and 100.8 p.m. in the following order: $\mathrm{La}^{3+}>\mathrm{Pr}^{3+}>$ $\mathrm{Nd}^{3+}>\mathrm{Sm}^{3+}>\mathrm{Eu}^{3+}>\mathrm{Gd}^{3+}>\mathrm{Tb}^{3+}>\mathrm{Dy}^{3+}>\mathrm{Er}^{3+}>\mathrm{Yb}^{3+}$. The level of the anatase to rutile phase transformation inhibition by RE doping is proportional with RE ionic radius. Anatase weight fraction slightly increased and anatase crystallite size decreased (significantly at $800^{\circ} \mathrm{C}$ ) with increasing $\mathrm{RE}$ ionic radius since larger $\mathrm{RE}$ ions have more inhibitory effect as discussed above and as shown in Fig. 19.

The crystallite sizes of $\mathrm{RE}_{2} \mathrm{Ti}_{2} \mathrm{O}_{7}$ phases in $5 \% \mathrm{RE}$ doped $\mathrm{TiO}_{2}$

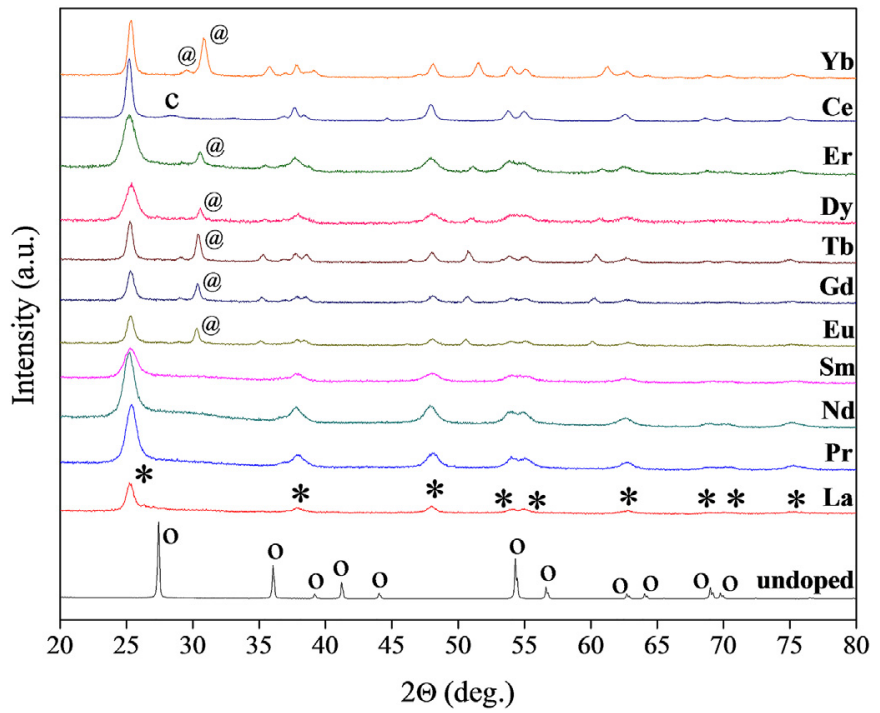

Fig. 18. XRD patterns of $5 \% \mathrm{RE}$ doped $\mathrm{TiO}_{2}$ powders heat treated at $800{ }^{\circ} \mathrm{C}$ ( $*$ : anatase, o: rutile, @: $\mathrm{RE}_{2} \mathrm{Ti}_{2} \mathrm{O}_{7}, \mathrm{c}: \mathrm{CeO}_{2}$ ).

powders heat treated at $800{ }^{\circ} \mathrm{C}$ are given in Fig. 20. The $\mathrm{RE}_{2} \mathrm{Ti}_{2} \mathrm{O}_{7}$ crystallite size increases with $\mathrm{RE}$ ionic radius indicating a 

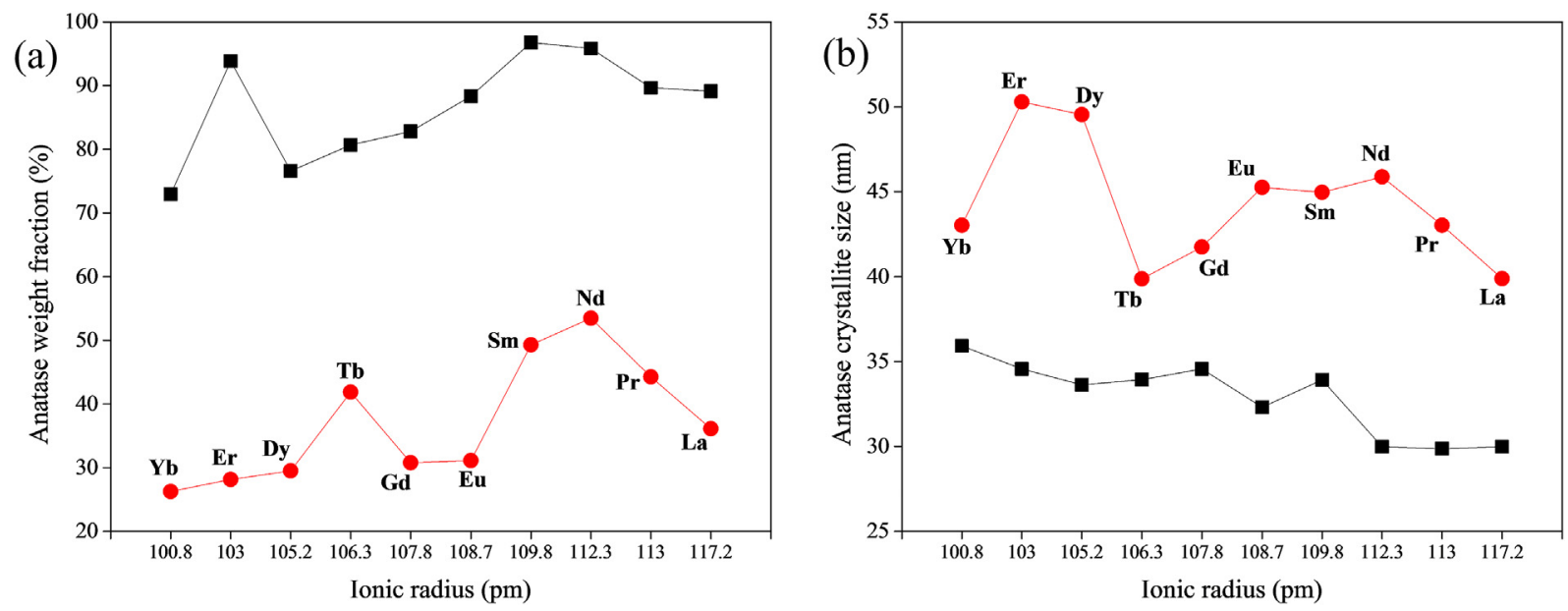

Fig. 19. (a) Anatase weight fractions (b) Anatase crystallite sizes of $0.1 \% \mathrm{RE}$ doped $\mathrm{TiO}_{2}$ powders heat treated at $(\boldsymbol{\square}) 700{ }^{\circ} \mathrm{C}$ and $(\bullet) 800{ }^{\circ} \mathrm{C}$.

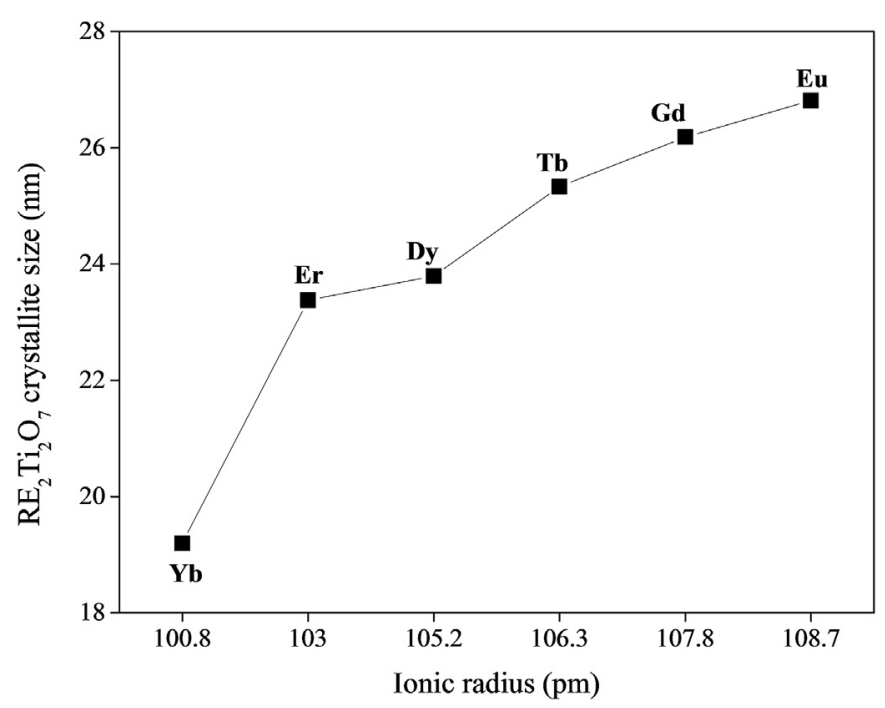

Fig. 20. Crystallite sizes of $\mathrm{RE}_{2} \mathrm{Ti}_{2} \mathrm{O}_{7}$ phases in $5 \% \mathrm{RE}$ doped $\mathrm{TiO}_{2}$ powders heat treated at $800{ }^{\circ} \mathrm{C}$.

dependence of the nucleation rate and crystal growth on RE ionic radius. The number of the nucleation sites decreases and the fewer number of nucleated $\mathrm{RE}_{2} \mathrm{Ti}_{2} \mathrm{O}_{7}$ crystallites grow to larger final sizes with increasing RE ionic radius.

The low temperature tentative phase diagrams of $\mathrm{RE}$ oxide- $\mathrm{TiO}_{2}$ systems in the temperature-composition plane are shown in Fig. 21. Data points are represented by stars ( 2 ). All the powders have anatase as the main phase at low heat treatment temperatures. Rutile was detected in the powders at $700{ }^{\circ} \mathrm{C}$ at doping levels up to $0.1 \%$ for large ionic radius (Nd, Pr, Sm) and up to $0.25 \%$ for relatively smaller ionic radius (Er, Dy) (corresponding values increased to $0.25 \%$ and $2 \%$, respectively at $800{ }^{\circ} \mathrm{C}$ ). $\mathrm{RE}_{2} \mathrm{Ti}_{2} \mathrm{O}_{7}$ phases were detected at $800^{\circ} \mathrm{C}$ above a doping level of $1 \%$. The $\mathrm{Nd} / \mathrm{Er}$ doped $\mathrm{TiO}_{2}$ powders were heat treated above $800{ }^{\circ} \mathrm{C}\left(900^{\circ} \mathrm{C}\right.$ and $\left.1000^{\circ} \mathrm{C}\right)$ in order to understanding the nanostructure better up to $1000^{\circ} \mathrm{C}$. Nd and Er with ionic radii of 112 and 103 p.m. was chosen for representation of $\mathrm{RE}$ behavior. $\mathrm{Er}_{2} \mathrm{Ti}_{2} \mathrm{O}_{7}$ was detected at doping levels higher than $0.1 \%$ at $900{ }^{\circ} \mathrm{C}$ and at all doping levels at $1000{ }^{\circ} \mathrm{C}$. $\mathrm{Nd}_{4} \mathrm{Ti}_{9} \mathrm{O}_{24}$ was detected beginning from $0.5 \%$ doping level at $900{ }^{\circ} \mathrm{C}$ and at all doping levels at $1000^{\circ} \mathrm{C}$. The dashed lined phase (single or multiphase regions) boundaries were drawn in between the data points. The points located on the phase boundaries represent the phase structure determined for XRD detectable phases. These tentative low temperature phase diagrams are expected to be useful to researchers working on the synthesis and application of these materials since currently high temperature ceramic phase diagrams are available which are not suitable for high surface area photocatalytic material nanostructure analysis.

The schematic representation of the proposed nanostructure evolution in $\mathrm{RE}$ doped $\mathrm{TiO}_{2}$ powders is given in Fig. 22. The dissolved RE nitrate ions in the gel structure may form RE/Ti nitratehydrate particles/films on the amorphous $\mathrm{TiO}_{2}$ domain boundaries upon drying of the gels. The $\mathrm{TiO}_{2}$ domains in the dried undoped powders may contain a significant level of organic groups. These groups may cause a significant substitutional carbon doping upon heat treatment of the amorphous powders due to anatase crystallization/densification and rutile phase transformation at relatively low temperatures. The presence of nitrate phases in the domain boundaries causes significant inhibition of the phase structure evolution. The domain boundary precursor phases thermally stabilize the anatase phase structure which causes significant removal of substitutional carbon through the open structure. The RE ions mainly located on the domain boundaries (partially in the interstitials) of the amorphous dried gel precursor transform into grain boundary RETiO phases upon heat treatment. The crystallite sizes of the phases present in the powders increase with the increase in the heat treatment temperature.

\section{Conclusions}

The effect of RE doping on the nanophase evolution/structure of sol-gel $\mathrm{TiO}_{2}$ were investigated by using DLS, XRD, XPS, $\mathrm{N}_{2}$ adsorption-desorption and HR-TEM.

Anatase was determined to be the main phase in all doped $\mathrm{TiO}_{2}$ powders up to $900{ }^{\circ} \mathrm{C}$. Rutile formation was observed beginning with $700{ }^{\circ} \mathrm{C}$ and rutile was the dominant phase with $\mathrm{RE}_{2} \mathrm{Ti}_{2} \mathrm{O}_{7}$ phases at $1000^{\circ} \mathrm{C} . \mathrm{RE}_{2} \mathrm{Ti}_{2} \mathrm{O}_{7}$ phases first appeared at $2 \%$ doping level at $800{ }^{\circ} \mathrm{C}$ for RE ions with small ionic radii (between $\mathrm{Eu}$ and $\mathrm{Yb}$ ). $\mathrm{Nd}_{4} \mathrm{Ti}_{9} \mathrm{O}_{24}$ phase was formed at $10 \%$ doping level at $800^{\circ} \mathrm{C}$ and even at low doping levels at $900{ }^{\circ} \mathrm{C}$ and $1000{ }^{\circ} \mathrm{C}$. It was found that the phase evolution from anatase to rutile was significantly inhibited by RE doping. The results indicated that RE ions may partially be located in the $\mathrm{TiO}_{2}$ lattice interstitial voids but mainly segregate on the grain boundaries of $\mathrm{TiO}_{2}$ crystallites. The formation of multiphase structures by RE doping may significantly affect the 

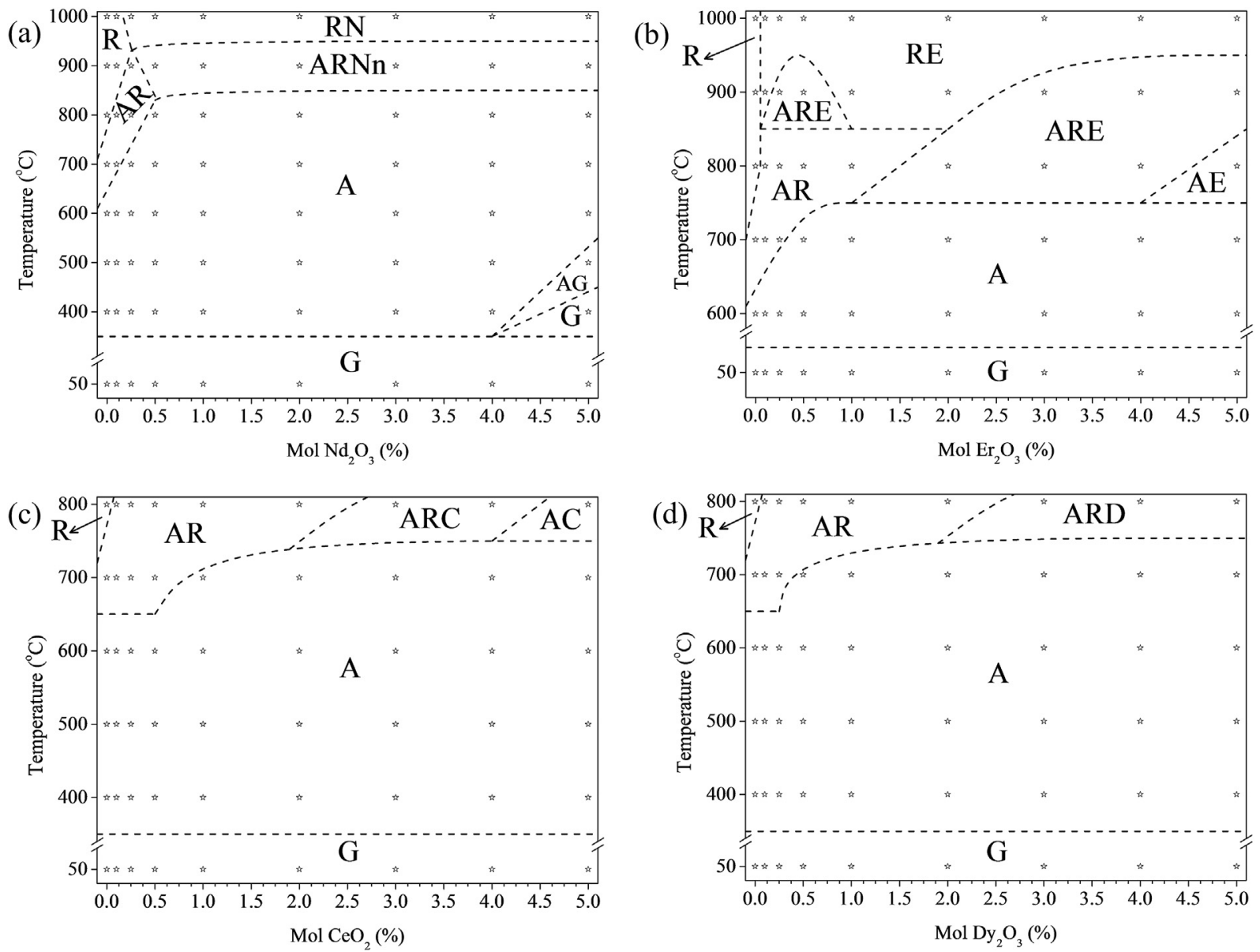

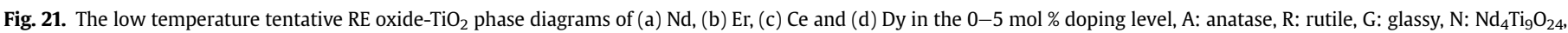
$\mathrm{n}$ : $\mathrm{Nd}_{2} \mathrm{Ti}_{4} \mathrm{O}_{11}$ (second Nd containing phase in minor amounts), $\mathrm{E}: \mathrm{Er}_{2} \mathrm{Ti}_{2} \mathrm{O}_{7}, \mathrm{C}: \mathrm{CeO}_{2}, \mathrm{D}: \mathrm{Dy}_{2} \mathrm{Ti}_{2} \mathrm{O}_{7}$.
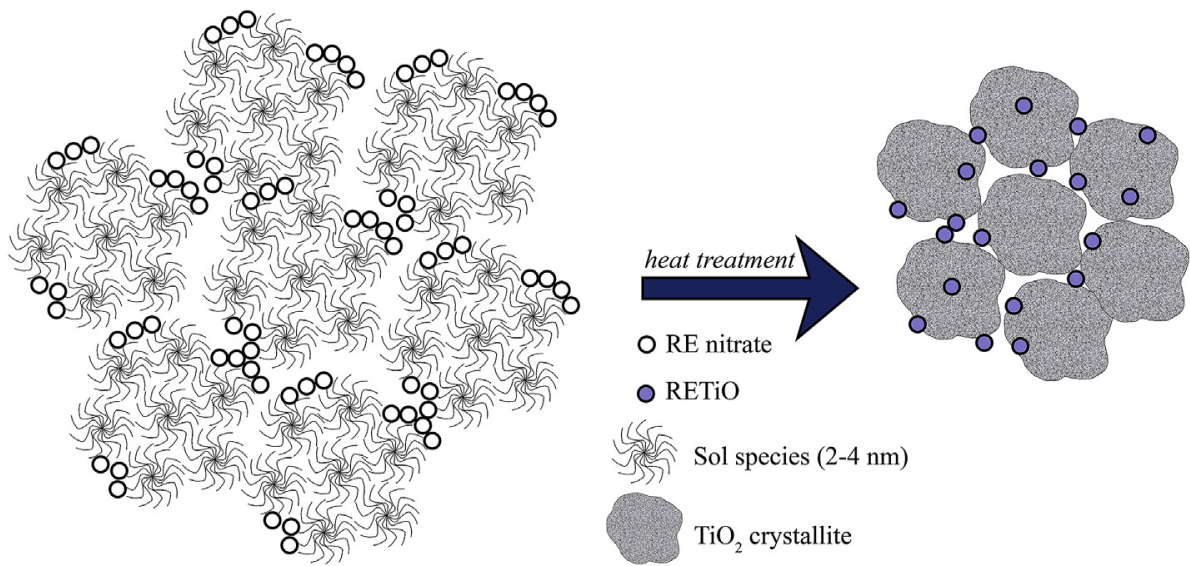

Fig. 22. Schematic representation of the proposed nanostructure evolution.

properties of the $\mathrm{TiO}_{2}$ based powders.

Phase analysis indicated that the RE ions mainly located on the domain boundaries (partially in the interstitials) of the amorphous dried gel precursor transform into grain boundary RETiO phases upon heat treatment.

Tentative low temperature phase diagrams were obtained and these diagrams may present a valuable tool to the researchers working on the synthesis and application of these materials.
Although some high temperature $\mathrm{RE}$ oxide- $\mathrm{TiO}_{2}$ phase diagrams are currently available they are not suitable for use below $1000{ }^{\circ} \mathrm{C}$ where $\mathrm{TiO}_{2}$ based powders are widely processed for use in applications like photocatalysis.

\section{Acknowledgements}

This study was supported by The Scientific and Technological 


\section{Research Council of Turkey (TUBITAK) within the context of Mühendislik Araştırma Grubu-Araştırma Destek Programları Başkanlığı (MAG-ARDEB) 110M739 project.}

\section{References}

[1] A. Fujishima, K. Honda, Electrochemical photolysis of water at a semiconductor electrode, Nature 238 (1972) 37-38.

[2] T. Inoue, A. Fujishima, S. Konishi, K. Honda, Photoelectrocatalytic reduction of carbon dioxide in aqueous suspensions of semiconductor powders, Nature 277 (1979) 637-638.

[3] D. Nassoko, Y.-F. Li, J.-L. Li, X. Li, Y. Yu, Neodymium-doped $\mathrm{TiO}_{2}$ with Anatase and Brookite two phases: mechanism for photocatalytic activity enhancement under visible light and the role of electron, Int. J. Photoenergy 2012 (2012) $1-10$.

[4] A. Bokare, M. Pai, A.A. Athawale, Surface modified Nd doped $\mathrm{TiO}_{2}$ nanoparticles as photocatalysts in UV and solar light irradiation, Sol. Energy 91 (2013) 111-119.

[5] C.-H. Chen, J. Shieh, H.-Y. Liao, J.-J. Shyue, Construction of titania-ceria nanostructured composites with tailored heterojunction for photocurrent enhancement, J. Eur. Ceram. Soc. 34 (2014) 1523-1535.

[6] C.H. Chiou, R.S. Juang, Photocatalytic degradation of phenol in aqueous solutions by Pr-doped $\mathrm{TiO}_{2}$ nanoparticles, J. Hazard Mater 149 (2007) 1-7.

[7] J. Castañeda-Contreras, V.F. Marañón-Ruiz, R. Chiu-Zárate, H. Pérez-Ladrón de Guevara, R. Rodriguez, C. Michel-Uribe, Photocatalytic activity of erbiumdoped $\mathrm{TiO}_{2}$ nanoparticles immobilized in macro-porous silica films, Mater Res. Bull. 47 (2012) 290-295.

[8] H.T. Gao, W.C. Liu, G.J. Liu, Facile synthesis and enhanced photocatalysis of Sm doped $\mathrm{TiO}_{2}$, Adv. Mater. Res. 490-495 (2012) 3272-3276.

[9] C.H. Liang, M.F. Hou, S.G. Zhou, F.B. Li, C.S. Liu, T.X. Liu, Y.X. Gao, X.G. Wang, J.L. Lu, The effect of erbium on the adsorption and photodegradation of orange I in aqueous $\mathrm{Er}^{3+}-\mathrm{TiO}_{2}$ suspension, J. Hazard. Mater. 138 (2006) 471-478.

[10] D. de la Cruz Romero, G.T. Torres, J.C. Arévalo, R. Gomez, A. Aguilar-Elguezabal, Synthesis and characterization of $\mathrm{TiO}_{2}$ doping with rare earths by sol-gel method: photocatalytic activity for phenol degradation, J. Sol-Gel Sci. Technol. 56 (2010) 219-226.

[11] O. Ruzimuradov, K. Sharipov, A. Yarbekov, K. Saidov, M. Hojamberdiev, R.M. Prasad, G. Cherkashinin, R. Riedel, A facile preparation of dual-phase nitrogen-doped $\mathrm{TiO}_{2}-\mathrm{SrTiO}_{3}$ macroporous monolithic photocatalyst for organic dye photodegradation under visible light, J. Eur. Ceram. Soc. 35 (2015) 1815-1821.

[12] C. Wang, Y. Ao, P. Wang, J. Hou, J. Qian, Preparation, characterization and photocatalytic activity of the neodymium-doped $\mathrm{TiO}_{2}$ hollow spheres, Appl. Surf. Sci. 257 (2010) 227-231.

[13] Q. Xiao, Z. Si, J. Zhang, C. Xiao, X. Tan, Photoinduced hydroxyl radical and photocatalytic activity of samarium-doped $\mathrm{TiO}_{2}$ nanocrystalline, J. Hazard. Mater. 150 (2008) 62-67.

[14] M.S. Hassan, T. Amna, O.B. Yang, H.-C. Kim, M.-S. Khil, $\mathrm{TiO}_{2}$ nanofibers doped with rare earth elements and their photocatalytic activity, Ceram. Int. 38 (2012) 5925-5930.

[15] Z. Jian, Y. Pu, J. Fang, Z. Ye, Microemulsion synthesis of nanosized $\mathrm{TiO}_{2}$ particles doping with rare-earth and their photocatalytic activity, Photochem. Photobiol. 86 (2010) 1016-1021.

[16] J. Reszczyńska, T. Grzyb, J.W. Sobczak, W. Lisowski, M. Gazda, B. Ohtani, A. Zaleska, Visible light activity of rare earth metal doped $\left(\mathrm{Er}^{3+}, \mathrm{Yb}^{3+} \mathrm{Or}^{3+} \mathrm{Er}^{3+}\right.$ $\mathrm{Yb}^{3+}$ ) titania photocatalysts, Appl. Catal. B-Environ. 163 (2015) 40-49.

[17] R.S. Ningthoujam, V. Sudarsan, R.K. Vatsa, R.M. Kadam, Jagannath, A. Gupta, Photoluminescence studies on Eu doped $\mathrm{TiO}_{2}$ nanoparticles, J. Alloys Compd. 486 (2009) 864-870.

[18] E. Setiawati, K. Kawano, T. Tsuboi, H.J. Seo, Studies on thermal migration of Eu ion doped into $\mathrm{TiO}_{2}$ nanoparticles, Jpn. J. Appl. Phys. 47 (2008) 4651-4657.

[19] S.I. Shah, W. Li, C.P. Huang, O. Jung, C. Ni, Study of $\mathrm{Nd}^{3+}, \mathrm{Pd}^{2+}, \mathrm{Pt}^{4+}$, and $\mathrm{Fe}^{3+}$ dopant effect on photoreactivity of $\mathrm{TiO}_{2}$ nanoparticles, Proc. Natl. Acad. Sci. U. S. A. 99 (Suppl 2) (2002) 6482-6486.

[20] F.B. Li, X.Z. Li, M.F. Hou, K.W. Cheah, W.C.H. Choy, Enhanced photocatalytic activity of $\mathrm{Ce}^{3+}-\mathrm{TiO}_{2}$ for 2-mercaptobenzothiazole degradation in aqueous suspension for odour control, Appl. Catal. A-Gen. 285 (2005) 181-189.

[21] W. Luo, R. Li, G. Liu, M.R. Antonio, X. Chen, Evidence of trivalent Europium incorporated in anatase $\mathrm{TiO}_{2}$ nanocrystals with multiple sites, J. Phys. Chem. C 112 (2008) 10370-10377.

[22] B. Shahmoradi, I.A. Ibrahim, N. Sakamoto, S. Ananda, R. Somashekar, T.N. Row, K. Byrappa, Photocatalytic treatment of municipal wastewater using modified neodymium doped $\mathrm{TiO}_{2}$ hybrid nanoparticles, J. Environ. Sci. Health A Tox Hazard. Subst. Environ. Eng. 45 (2010) 1248-1255.

[23] Ž. Antić, R.M. Krsmanović, M.G. Nikolić, M. Marinović-Cincović, M. Mitrić, S. Polizzi, M.D. Dramićanin, Multisite luminescence of rare earth doped $\mathrm{TiO}_{2}$ anatase nanoparticles, Mater Chem. Phys. 135 (2012) 1064-1069.

[24] A. Burns, G. Hayes, W. Li, J. Hirvonen, J.D. Demaree, S.I. Shah, Neodymium ion dopant effects on the phase transformation in sol-gel derived titania nanostructures, Mater. Sci. Eng-B 111 (2004) 150-155.

[25] L.G. Devi, S.G. Kumar, Exploring the critical dependence of adsorption of various dyes on the degradation rate using $\mathrm{Ln}^{3+}-\mathrm{TiO}_{2}$ surface under UV/solar light, Appl. Surf. Sci. 261 (2012) 137-146.
[26] P. Ghigna, A. Speghini, M. Bettinelli, “Unusual $\mathrm{Ln}^{3+}$ substitutional defects": the local chemical environment of $\mathrm{Pr}^{3+}$ and $\mathrm{Nd}^{3+}$ in nanocrystalline $\mathrm{TiO}_{2}$ by $\mathrm{Ln}-\mathrm{K}$ edge EXAFS, J. Solid State Chem. 180 (2007) 3296-3301.

[27] W. Li, A.I. Frenkel, J.C. Woicik, C. Ni, S.I. Shah, Dopant location identification in $\mathrm{Nd}^{3+}$-doped $\mathrm{TiO}_{2}$ nanoparticles, Phys. Rev. B 72 (2005), 155315/1-6.

[28] S. Obregón, A. Kubacka, M. Fernández-García, G. Colón, High-performance $\mathrm{Er}^{3+}-\mathrm{TiO}_{2}$ system: dual up-conversion and electronic role of the lanthanide, J. Catal. 299 (2013) 298-306.

[29] Y. Xin, H. Liu, Study on mechanism of photocatalytic performance of La-doped $\mathrm{TiO}_{2} / \mathrm{Ti}$ photoelectrodes by theoretical and experimental methods, J. Solid State Chem. 184 (2011) 3240-3246.

[30] M. Borlaf, M.T. Colomer, R. Moreno, A. de Andrés, B. Hintzen, Structural and photoluminescence study of $\mathrm{Eu}^{3+} / \mathrm{TiO}_{2}$ xerogels as a function of the temperature using optical techniques, J. Am. Ceram. Soc. 98 (2015) 338-345.

[31] M. Jin, Y. Nagaoka, K. Nishi, K. Ogawa, S. Nagahata, T. Horikawa, M. Katoh, T. Tomida, J.i. Hayashi, Adsorption properties and photocatalytic activity of $\mathrm{TiO}_{2}$ and La-doped $\mathrm{TiO}_{2}$, Adsorption 14 (2008) 257-263.

[32] Y. Zhang, H. Zhang, Y. Xu, Y. Wang, Significant effect of lanthanide doping on the texture and properties of nanocrystalline mesoporous $\mathrm{TiO}_{2}$, J. Solid State Chem. 177 (2004) 3490-3498.

[33] W. Gong, R. Zhang, Phase relationship in the $\mathrm{TiO}_{2}-\mathrm{Nd}_{2} \mathrm{O}_{3}$ pseudo-binary system, J. Alloys Compd. 548 (2013) 216-221.

[34] S.D. Škapin, D. Kolar, D. Suvorov, Phase stability and equilibria in the $\mathrm{La}_{2} \mathrm{O}_{3}-\mathrm{TiO}_{2}$ system, J. Eur. Ceram. Soc. 20 (2000) 1179-1185.

[35] J. Zhou, G. Tian, Y. Chen, J.Q. Wang, X. Cao, Y. Shi, K. Pan, H. Fu, Synthesis of hierarchical $\mathrm{TiO}_{2}$ nanoflower with anatase-rutile heterojunction as Ag support for efficient visible-light photocatalytic activity, Dalton Trans. 42 (2013) $11242-11251$.

[36] D.C. Hurum, A.G. Agrios, K.A. Gray, T. Rajh, M.C. Thurnauer, Explaining the enhanced photocatalytic activity of degussa P25 mixed-phase $\mathrm{TiO}_{2}$ using EPR, J. Phys. Chem. B 107 (2003) 4545-4549.

[37] R.A. Spurr, H. Myers, Quantitative analysis of anatase-rutile mixtures with an X-ray diffractometer, Anal. Chem. 29 (1957) 760-762.

[38] A.K. Tripathi, M.K. Singh, M.C. Mathpal, S.K. Mishra, A. Agarwal, Study of structural transformation in $\mathrm{TiO}_{2}$ nanoparticles and its optical properties, J. Alloys Compd. 549 (2013) 114-120.

[39] C.D. Wagner, L.E. Davis, M.V. Zeller, J.A. Taylor, R.H. Raymond, L.H. Gale, Empirical atomic sensitivity factors for quantitative analysis by electron spectroscopy for chemical analysis, Surf. Interface Anal. 3 (1981) 211-225.

[40] D.A.H. Hanaor, C.C. Sorrell, Review of the anatase to rutile phase transformation, J. Mater Sci. 46 (2010) 855-874.

[41] D.M. Tobaldi, R.C. Pullar, A.F. Gualtieri, A. Belen Jorge, R. Binions, P.F. McMillan, M.P. Seabra, J.A. Labrincha, Influence of sol counter-ions on the anatase-torutile phase transformation and microstructure of nanocrystalline $\mathrm{TiO}_{2}$ CrystEngComm 17 (2015) 1813-1825.

[42] S. Mondal, R. Madhuri, P.K. Sharma, PVA assisted low temperature anatase to rutile phase transformation (ART) and properties of titania nanoparticles, J. Alloys Compd. 646 (2015) 565-572.

[43] A. Maurya, P. Chauhan, S.K. Mishra, R.K. Srivastava, Structural, optical and charge transport study of rutile $\mathrm{TiO}_{2}$ nanocrystals at two calcination temperatures, J. Alloys Compd. 509 (2011) 8433-8440.

[44] A.A. Gribb, J.F. Banfield, Particle size effects on transformation kinetics and phase stability in nanocrystalline $\mathrm{TiO}_{2}$, Am. Mineral. 82 (1997) 717-728.

[45] H. Zhang, J.F. Banfield, Understanding polymorphic phase transformation behavior during growth of nanocrystalline aggregates: insights from $\mathrm{TiO}_{2}$ J. Phys. Chem. B 104 (2000) 3481-3487.

[46] M. Borlaf, M.T. Colomer, R. Moreno, A.L. Ortiz, Effect of $\mathrm{Er}^{3+}$ doping on the thermal stability of $\mathrm{TiO}_{2}$ nanoparticulate xerogels, J. Nanopart Res. 15 (2013) $1752 / 1-10$.

[47] M. Borlaf, M.T. Colomer, R. Moreno, A.L. Ortiz, Rare earth-doped $\mathrm{TiO}_{2}$ nanocrystalline thin films: preparation and thermal stability, J. Eur. Ceram. Soc. 34 (2014) 4457-4462.

[48] C.P. Sibu, S.R. Kumar, P. Mukundan, K.G.K. Warrier, Structural modifications and associated properties of lanthanum oxide doped sol-gel nanosized titanium oxide, Chem. Mater. 14 (2002) 2876-2881.

[49] S. Asal, M. Saif, H. Hafez, S. Mozia, A. Heciak, D. Moszyński, M.S.A. AbdelMottaleb, Photocatalytic generation of useful hydrocarbons and hydrogen from acetic acid in the presence of lanthanide modified $\mathrm{TiO}_{2}$, Int. J. Hydrog. Energy 36 (2011) 6529-6537.

[50] M. Saif, M.S.A. Abdel-Mottaleb, Titanium dioxide nanomaterial doped with trivalent lanthanide ions of Tb, Eu and Sm: preparation, characterization and potential applications, Inorg. Chim. Acta 360 (2007) 2863-2874.

[51] D.M. Tobaldi, R.C. Pullar, A.S. Škapin, M.P. Seabra, J.A. Labrincha, Visible light activated photocatalytic behaviour of rare earth modified commercial $\mathrm{TiO}_{2}$ Mater. Res. Bull. 50 (2014) 183-190.

[52] J. Zhang, L.J. Xu, Z.Q. Zhu, Q.J. Liu, Synthesis and properties of (Yb, N)-TiO photocatalyst for degradation of methylene blue (MB) under visible light irradiation, Mater. Res. Bull. 70 (2015) 358-364.

[53] R.D. Dominguez, G. Alarcón-Flores, M. Aguilar-Frutis, R.I. Sánchez-Alarcón, C. Falcony, H.J. Dorantes-Rosales, J.L. González-Velázquez, D.I. Rivas-López, Effect on the stabilization of the anatase phase and luminescent properties of samarium-doped $\mathrm{TiO}_{2}$ nanocrystals prepared by microwave irradiation, J. Alloys Compd. 687 (2016) 121-129.

[54] M.R. Mohammadi, D.J. Fray, Synthesis and characterisation of nanostructured neodymium titanium oxides by sol-gel process: controlling the phase 
composition, crystal structure and grain size, Mater. Chem. Phys. 122 (2010) $512-523$.

[55] V. Swamy, D. Menzies, B.C. Muddle, A. Kuznetsov, L.S. Dubrovinsky, Q. Dai, V. Dmitriev, Nonlinear size dependence of anatase $\mathrm{TiO}_{2}$ lattice parameters
Appl. Phys. Lett. 88 (2006) 243103

[56] B. Choudhury, A. Choudhury, Local structure modification and phase transformation of $\mathrm{TiO}_{2}$ nanoparticles initiated by oxygen defects, grain size, and annealing temperature, Int. Nano Lett. 3 (2013) 1-9. 